\title{
Estudio sobre el catecismo pictográfico mazahua
}

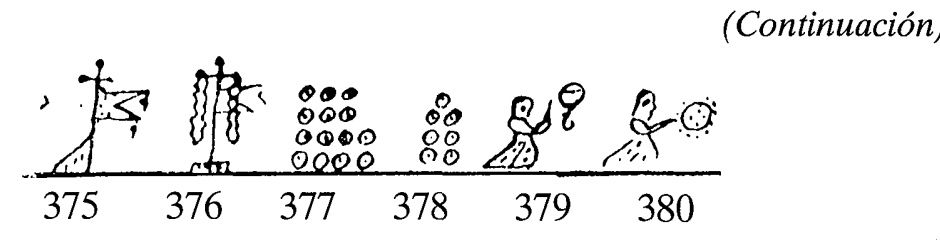

\section{DECIMA PARTE}

\section{ARTICULOS DE LA FE}

El presente apartado viene a ser una duplicación del contenido del credo, salvando algunas ligeras diferencias. Pero la solera de que gozaba era tan notable que ni siquiera se ponía en tela de juicio la conveniencia de omitirlo, una vez que se había propuesto el credo en un catecismo. Por esta razón, este Catecismo, como otros muchos, recoge en sus páginas el doble formulario. Apenas tiene dificultad de interpretación, desde el momento que la práctica totalidad de sus expresiones han aparecido ya en el credo.

\section{Pictograma 375}

Un estandarte igual a los que figuraban en el pictograma 277 significa en esta ocasión: artículos.

\section{Pictograma 376}

Igual a pictograma 76. Significa: $f e$.

\section{Pictograma 377}

Aparecen tres hileras verticales de cuatro circulitos cada una, más otros dos a la derecha. Su sentido es: catorce

\section{Pictograma 378}

Igual a pictograma 286. Significa: siete

\section{Pictograma 379}

Una persona arrodillada señala hacia un pequeño círculo que hay en la parte superior derecha del pictograma; dicho círculo tiene un apéndice curvo; podría tratarse de una pequeña flor. El significado que mejor encaja es: para.

\section{Pictograma 380}

Igual a pictograma 258. Significa: el nombre. 


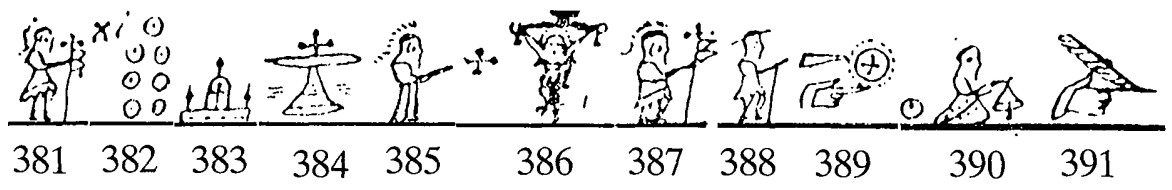

Pictograma 381

Igual a pictograma 27. Significa: Dios.

Pictograma 382

Igual a pictograma 286. Significa: siete.

\section{Pictograma 383}

Una representación de lo que se podría entender como un altar visto de frente, constituido por una mesa, sobre la cual estaría en la parte central el sagrario. Su significado podría ser: venerada.

\section{Pictograma 384}

Una extraña representación, que en cierto modo recuerda la pila bautismal del pictograma 360, de la cual, sin embargo, difiere: sobre una peana aparece un objeto alargado, encima del cual aparece una cruz. Su sentido, por el contexto, tendría que ser: humanidad.

\section{Pictograma 385}

Igual a pictograma 57. Significa: Señor.

\section{Pictograma 386}

Igual a pictograma 11. Significa: Jesucristo.

\section{Pictograma 387}

Igual a pictograma 27. Significa: Dios.

\section{Pictograma 388}

Igual a pictograma 160. Significa: hombre.

\section{Pictograma 389}

Igual a pictograma 2. Significa: verdadero.

\section{Pictograma 390}

Igual a pictograma 13. Significa: entonces.

\section{Pictograma 391}

Igual a pictograma 19. Significa: así como. 


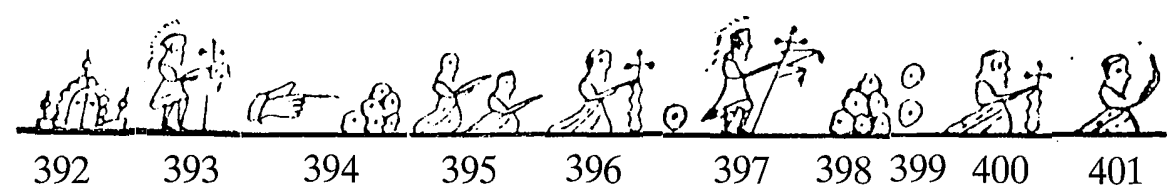

Pictograma 392

Parecido al pictograma 383, con un adorno en la parte central del sagrario. Podría significar: venerado.

\section{Pictograma 393}

Igual a pictograma 27. Significa: Dios.

\section{Pictograma 394}

Pictograma compuesto de la mano del pictograma 68, más un conjunto confuso que bien puede ser el pictograma 2. El significado es: todos estos.

\section{Pictograma 395}

Igual a pictograma 257. Significa: el primero.

\section{Pictograma 396}

Igual a pictograma 3. Significa: creer.

\section{Pictograma 397}

Igual a pictograma 27, más el añadido de un circulito a la izquierda del pictograma, que representa la unidad. Significa: (en) un único Dios.

\section{Pictograma 398}

Igual a pictograma 1. Significa: todo.

Curiosamente el tlacuilo ha sufrido un despiste, porque este pictograma tendría que haberse visto seguido del pictograma 50 ("hacedor"), para representar como en otras ocasiones la idea completa. Sin embargo, ha omitido este segundo pictograma.

\section{Pictograma 399}

Igual a pictograma 269. Significa: el segundo.

\section{Pictograma 400}

Igual a pictograma 3. Significa: creer.

\section{Pictograma 401}

Similar a pictograma 16. Aunque allí le cuadra el significado de la preposición "por", aquí, en todos los artículos relativos a la divinidad, el más aconsejable es: que es, que hay. 


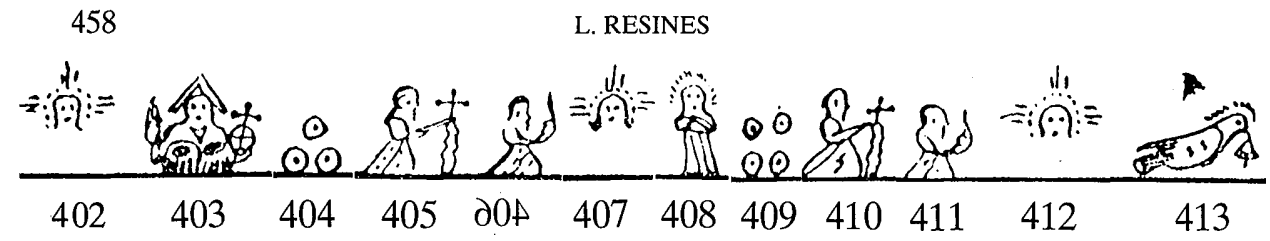

Pictograma 402

Igual a pictograma 124. Significa: divinidad.

Pictograma 403

Igual a pictograma 61. Significa: Padre.

Pictograma 404

Igual a pictograma 274. Significa: el tercero.

Pictograma 405

Igual a pictograma 3. Significa: creer.

Pictograma 406

Igual a pictograma 401. Significa: que es.

Pictograma 407

Igual a pictograma 124. Significa: divinidad.

Pictograma 408

Igual a pictograma 62. Significa: Hijo.

Pictograma 409

Igual a pictograma 278. Significa: el cuarto.

Pictograma 410

Igual a pictograma 3. Significa: creer.

Pictograma 411

Igual a pictograma 401. Significa: que es.

\section{Pictograma 412}

Igual a pictograma 124. Significa: divinidad.

\section{Pictograma 413}

Igual a pictograma 63. Significa: Espíritu Santo. 


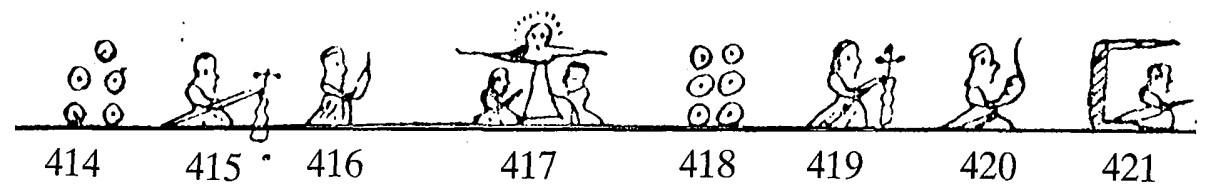

Pictograma 414

Igual a pictograma 282. Significa: el quinto.

Pictograma 415

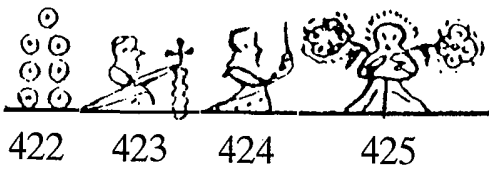

Igual a pictograma 3. Significa: creer.

\section{Pictograma 416}

Igual a pictograma 401. Significa: que es.

\section{Pictograma 417}

Igual a pictograma 150. Significa: creador.

\section{Pictograma 418}

Igual a pictograma 284. Significa: el sexto.

\section{Pictograma 419}

Igual a pictograma 3. Significa: creer.

\section{Pictograma 420}

Igual a pictograma 401. Significa: que es.

\section{Pictograma 421}

Igual a pictograma 17. Significa: salvar, (el que) salva.

\section{Pictograma 422}

Igual a pictograma 286. Significa: el séptimo.

\section{Pictograma 423}

Igual a pictograma 3. Significa: creer.

\section{Pictograma 424}

Igual a pictograma 401. Significa: que es.

\section{Pictograma 425}

Igual a pictograma 120. Significa: (el que) glorifica. 


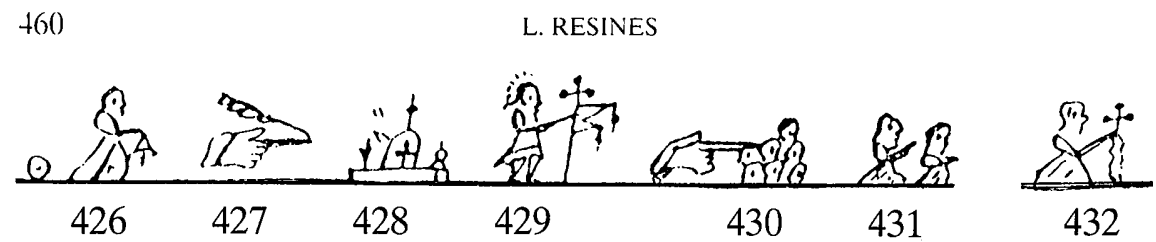

Pictograma 426

Igual a pictograma 13. Significa: entonces.

Pictograma 427

Igual a pictograma 19. Significa: así como.

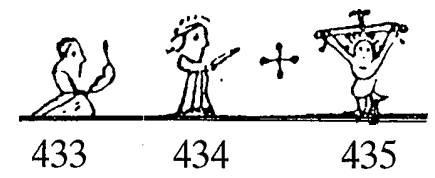

Pictograma 428

Igual a pictograma 383. Significa: venerado.

\section{Pictograma 429}

Igual a pictograma 27. Significa: Dios.

Aquí se detecta un error, puesto que ha dividido los artículos de la fe en las dos series consabidas, de la divinidad y de la humanidad de Jesucristo (pictogramas 378-389). Lógicamente, desarrolla en primer lugar los de la divinidad, enunciados en los pictogramas 390-393, que en versión según el sentido, serían "los que corresponden a Dios". Por lo tanto, ahora tendrían que venir los que corresponden a Jesucristo, Dios y hombre. Sin embargo, el presente pictograma omite la referencia a Jesucristo, para presentar de nuevo la imagen de Dios.

\section{Pictograma 430}

Igual a pictograma 394. Significa: (son) todos estos.

\section{Pictograma 431}

Igual a pictograma 257. Significa: el primero.

\section{Pictograma 432}

Igual a pictograma 3. Significa: creer.

\section{Pictograma 433}

Igual a pictograma 401. Significa: que es.

Pictograma 434

Igual a pictograma 57. Significa: Señor.

\section{Pictograma 435}

Igual a pictograma 11. Significa: Jesucristo. 


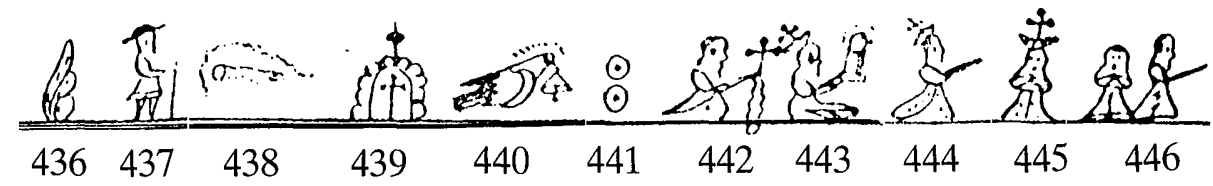

Pictograma 436

Igual a pictograma 50. Significa: hecho.

\section{Pictograma 437}

Igual a pictograma 160 . Significa: hombre.

\section{Pictograma 438}

Un leño o tronco (no es muy apreciable el dibujo) rodeado por la parte superior, de una aureola de puntos. El significado que encaja aquí, de conformidad con el contexto del formulario, es: (se) encarnó.

\section{Pictograma 439}

Igual a pictograma 161. Significa: obra.

\section{Pictograma 440}

Igual a pictograma 63. Significa: Espíritu Santo.

\section{Pictograma 441}

Igual a pictograma 269. Significa: el segundo.

\section{Pictograma 442}

Igual a pictograma 3. Significa: creer.

\section{Pictograma 443}

Una figura como la que representa a María sostiene en su brazo extendido una pequeña figura con aureola, que hay que suponer (aunque el dibujo apenas deje lugar a ello) que se trata de su hijo. Su significado es: nació.

\section{Pictograma 444}

Igual a pictograma 132. Significa: santa.

\section{Pictograma 445}

Igual a pictograma 133. Significa: María.

\section{Pictograma 446}

Pictograma compuesto: la primera figura es parecida a pictograma 211 , pero la diferencia estriba en que carece de aureola; la segunda figura representa a una persona con el brazo extendido. El conjunto del pictograma podría significar: es (por) siempre. 


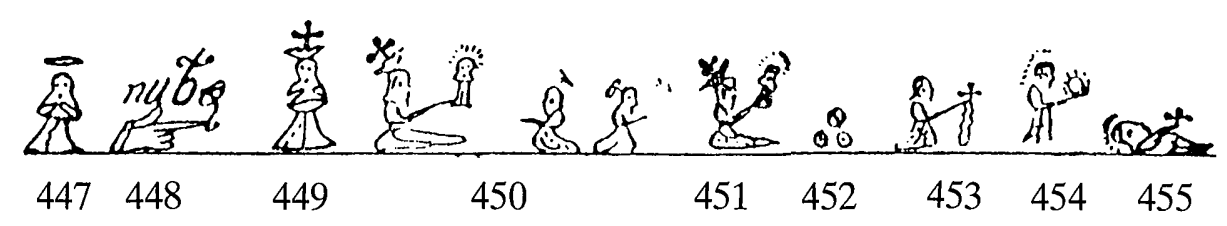

\section{Pictograma 447}

Parecido a pictograma 211, la figura carece de la aureola que aparecía en aquel pictograma; pero a diferencia del pictograma 446, aquí aparece con una corona elíptica. El sentido que encaja, por el contexto, es: virgen.

(Puede verse el pictograma 240, en que el contexto aconseja atribuir el significado de "virgen", aunque cambie el tipo de corona respecto al presente pictograma).

\section{Pictograma 448}

Igual a pictograma 46, más la leyenda "nubq". Significa: manda.

\section{Pictograma 449}

Igual a pictograma 133. Significa: María.

\section{Pictograma 450}

Es un pictograma compuesto: la primera parte es igual al pictograma 443; en la parte derecha del pictograma, aparece un personaje arrodillado y con corona, que señala hacia la parte primera. Su sentido podría ser: en el parto.

\section{Pictograma 451}

Parecido al pictograma anterior, los personajes invierten el orden. Su sentido, pues, sería: después del parto.

\section{Pictograma 452}

Igual a pictograma 274. Significa: el tercero.

\section{Pictograma 453}

Igual a pictograma 3. Significa: creer.

\section{Pictograma 454}

Igual a pictograma 57. Significa: Señor.

\section{Pictograma 455}

Igual a pictograma 15. Significa: murió. 


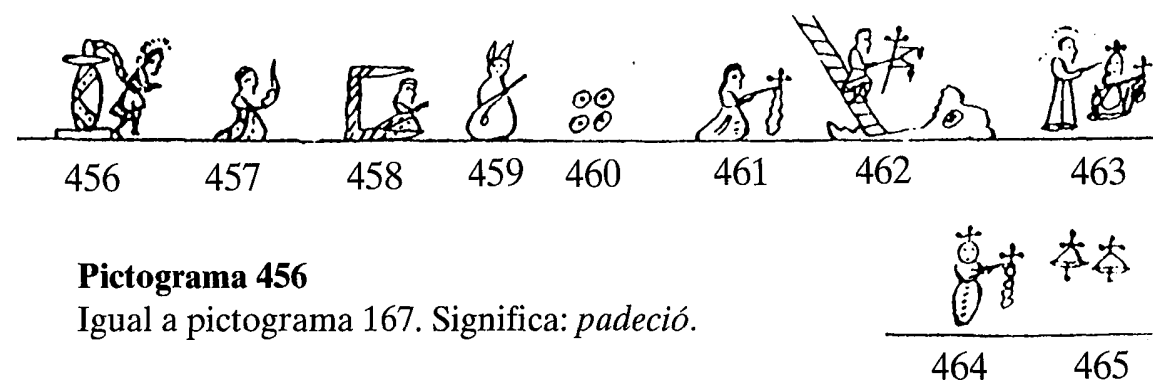

\section{Pictograma 457}

Igual a pictograma 32. Significa: por.

\section{Pictograma 458}

Igual a pictograma 33. Significa: librar.

\section{Pictograma 459}

Igual a pictograma 18. Significa: pecado.

\section{Pictograma 460}

Igual a pictograma 278. Significa: el cuarto.

\section{Pictograma 461}

Igual a pictograma 3. Significa: creer.

\section{Pictograma 462}

Igual a pictograma 174. Significa: bajó a los infiernos.

\section{Pictograma 463}

Pictograma en que una figura como la del pictograma 57 está casi tocando una segunda figura de la que apenas se perciben los rasgos con detalle, pero que se muestra con más claridad en el pictograma siguiente. El sentido, acomodado al desarrollo del formulario, ha de ser: sacó.

\section{Pictograma 464}

Una figura como la que ocupaba el segundo lugar en el pictograma anterior: se trata de una informe representación que tiene un rostro redondo sobre el que hay una cruz, más un tronco y una piernas que más bien recuerdan el abdomen de un insecto. Tiene extendida una mano, de la que pende una hilera de cuatro pequeños círculos, con una cruz en su extremo superior. El sentido del formulario está señalando su sentido: las almas

\section{Pictograma 465}

Igual a pictograma 198. Significa: santos. 


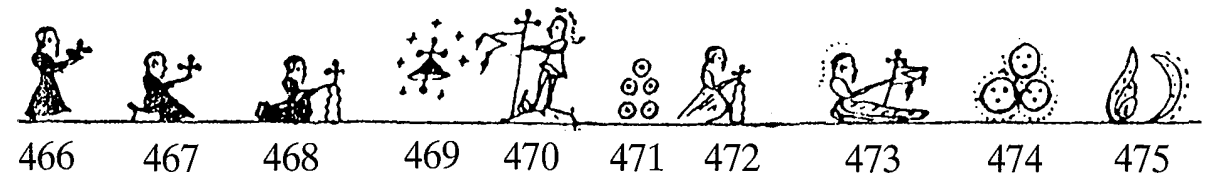

\section{Pictograma 466}

Una figura con el vestido obscuro, y los brazos estirados sosteniendo una cruz. Recuerda a pictograma 86 y 370 . Su sentido es: padres.

\section{Pictograma 467}

Parecida a pictograma 86 una persona con vestido obscuro (como en el pictograma anterior y en el siguiente) está sentada; pero su actitud inequívocamente se identifica con la del pictograma 213. Su sentido es: esperaban.

\section{Pictograma 468}

Igual a pictograma 3, aunque la persona, como en los dos pictogramas anteriores, tenga vestido obscuro. Significa: creían.

\section{Pictograma 469}

Mezcla de los pictogramas 198 (campana = santa) y 123 (corona de crucecitas = gracia). El sentido del pictograma es: santa y graciosa, o santa y bendita.

\section{Pictograma 470}

Igual a la segunda parte del pictograma 186. Significa: llegada.

\section{Pictograma 471}

Igual a pictograma 282. Significa: el quinto.

\section{Pictograma 472}

Igual a pictograma 3. Significa: creer.

\section{Pictograma 473}

Igual a pictograma 176. Significa: resucitó.

\section{Pictograma 474}

Igual a pictograma 175. Significa: al tercer día.

\section{Pictograma 475}

Igual a pictograma 177. Significa: de entre. 


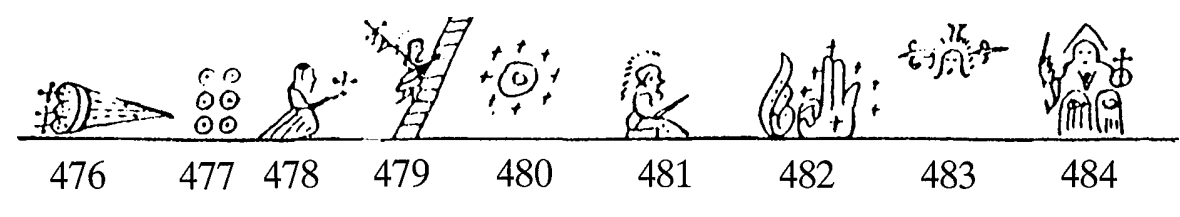

Pictograma 476

Igual a pictograma 178. Significa: muertos.

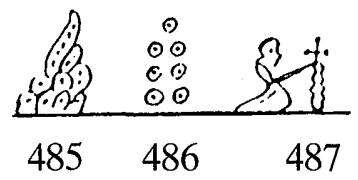

\section{Pictograma 477}

Igual a pictograma 284. Significa: el sexto.

\section{Pictograma 478}

Igual a pictograma 3. Significa: creer.

\section{Pictograma 479}

Igual a pictograma 179. Significa: subió.

\section{Pictograma 480}

Igual a pictograma 180 . Significa: cielo.

\section{Pictograma 481}

Igual a pictograma 181. Significa: sentado.

\section{Pictograma 482}

Igual a pictograma 182. Significa: a la bendita mano derecha.

\section{Pictograma 483}

Igual a pictograma 124. Significa: divinidad.

\section{Pictograma 484}

Igual a pictograma 61. Significa: Padre.

\section{Pictograma 485}

Se produce una fusión de los pictogramas 1 y 50 , que ordinariamente aparecían en dos pictogramas diversos. Significa: todohacedor.

\section{Pictograma 486}

Igual a pictograma 286. Significa: el séptimo.

\section{Pictograma 487}

Igual a pictograma 3. Significa: creer. 


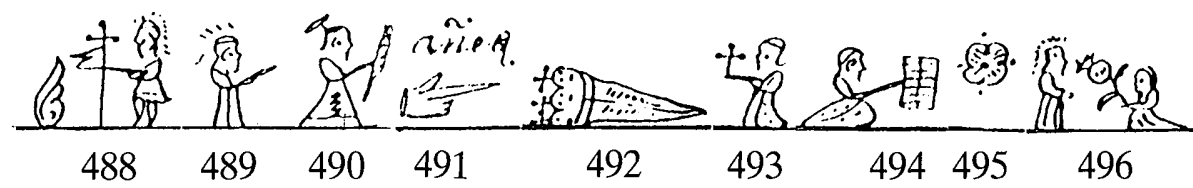

Pictograma 488

Igual a pictograma 186. Significa: desde allí vendrá.

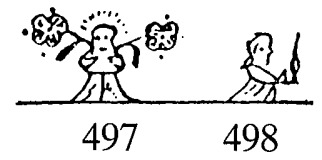

\section{Pictograma 489}

Igual a pictograma 188. Significa: juzgar.

\section{Pictograma 490}

Igual a pictograma 189. Significa: vivos.

\section{Pictograma 491}

Igual a pictograma 68 , con la inscripción borrosa "añeq". Significa: $y$ también.

\section{Pictograma 492}

Igual a pictograma 178. Significa: muertos.

\section{Pictograma 493}

Pictograma igual a pictograma 81 , pero dibujado en sentido invertido, mirando hacia la izquierda. Su sentido, de acuerdo con el formulario de los artículos de la fe, sería: $a$ saber.

\section{Pictograma 494}

Igual a pictograma 24. Significa: buenos.

\section{Pictograma 495}

Igual a pictograma 80. Significa: provecho.

\section{Pictograma 496}

Pictograma en el que la figura primera, correspondiente al pictograma 57 ("Señor") está frente a una persona arrodillada, que tiene en sus manos una gran flor. Su sentido podría ser: premio.

\section{Pictograma 497}

Igual a pictograma 208. Significa: gloria.

\section{Pictograma 498}

Igual a pictograma 32. Significa: por, porque. 


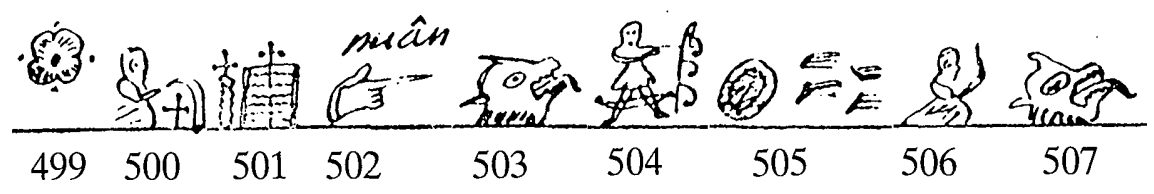

Pictograma 499

Igual a pictograma 80 . Significa: provecho.

Pictograma 500

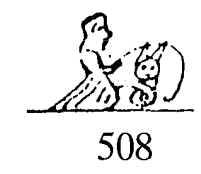

Igual a pictograma 273. Significa: respetar.

\section{Pictograma 501}

Igual a pictograma 77. Significa: mandamientos.

\section{Pictograma 502}

Igual a pictograma 68; consta en la parte superior la leyenda "nuân". Significa: y también.

\section{Pictograma 503}

Igual a pictograma 22. Significa: malos.

\section{Pictograma 504}

Una persona en pie tiene los pies aherrojados, y las manos (aunque sea menos perceptible) igualmente atadas a un poste vertical, con unas inflorescencias que salen hacia la derecha. Su sentido es: prisión.

\section{Pictograma 505}

Pictograma compuesto de un doble círculo, con el interior obscurecido por una serie desordenada de trazos; a su lado, la misma representación del pictograma 204. Su significado es: castigo (para) siempre.

\section{Pictograma 506}

Igual a pictograma 32. Significa: por, porque.

\section{Pictograma 507}

Igual a pictograma 22. Significa: malos.

\section{Pictograma 508}

Una representación similar a la del pictograma 273, pero en el espacio generado entre la persona arrodillada y el trazo que cae desde su mano hasta el suelo, en lugar de la representación de la cruz aparece la representación del pecado (pictograma 18). Su sentido es: pecaron. 


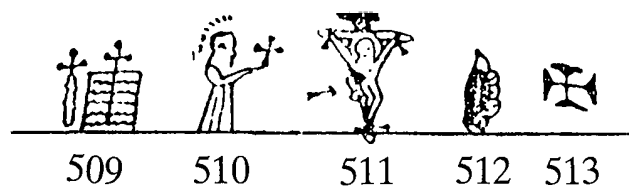

\section{Pictograma 509}

Igual a pictograma 77. Significa: mandamientos.

\section{Pictograma 510}

Igual a pictograma 57. Significa: Señor.

\section{Pictograma 511}

Igual a pictograma 11. Significa: Jesucristo.

Aquí se invierte el sentido de la lectura de la última banda correspondiente a los artículos de la fe, indicando una flechita esta circunstancia.

\section{Pictograma 512}

Igual a pictograma 50. Significa: (se) haga.

\section{Pictograma 513}

Igual a pictograma 118. Significa: Jesús.

Descifrada la totalidad de los pictogramas de este formulario, su versión queda de la siguiente forma: Los artículos de la fe (son) catorce. Siete para el nombre de Dios; siete (para) la venerada humanidad (?) del Señor Jescristo, Dios (y) hombre verdadero. Entonces, así (los) del venerado Dios (son) todos estos: El primero, creer (en) un único Dios todo(hacedor). El segundo, creer que es la divinidad del Padre. El tercero, creer que es la divinidad del Hijo. El cuarto, creer que es la divinidad del Espíritu Santo. El quinto, creer que es creador. El sexto, creer que salva. El séptimo, creer que glorifica.

Entonces, así (los) del venerado Dios (son) todos estos: El primero, creer que el Señor Jesucristo (se) hizo hombre, encarnó (?) por obra del Espíritu Santo. El segundo, creer que nació (de) santa María (que) es siempre virgen, (según) (lo) mandado María en el parto (y) después del parto. El tercero, creer que el Señor murió, padeció por liberar(nos) (del) pecado. El cuarto, creer que descendió a los infiernos; el Señor sacó las ánimas de los santos padres (que) esperaban (y) creían su santa (y) bendita llegada. El quinto, creer que resucitó al tercer día de entre los muertos. El sexto, creer que subió al cielo, sentado a la bendita mano derecha de la divinidad del Padre todohacedor. El séptimo creer que desde allí vendrá a juzgar a vivos y también muertos, a saber, (a) los buenos aprovechará el premio de la gloria, porque aprovecharon (a) respetar los mandamientos; y también (a) los malos a la prisión del castigo eterno, porque los malos pecaron (contra) los mandamientos del Señor Jesucristo. (Así) se haga, Jesús. 


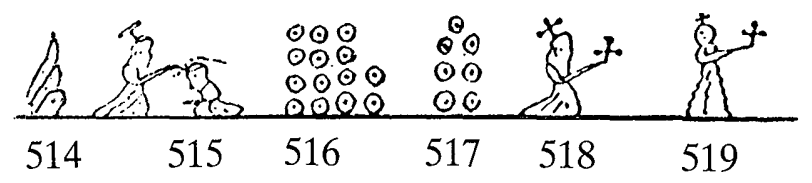

\section{UNDECIMA PARTE}

\section{OBRAS DE MISERICORDIA}

En términos generales, las obras de misericordia no presentan grandes problemas de interpretación, de manera que su formulario discurre dentro de la normalidad de una brevedad de conceptos, y un simple enunciado de cada uno de los comportamientos propuestos para llevar a cabo una actuación cristiana generosa de cara al prójimo.

\section{Pictograma 514}

Igual a pictograma 50. Significa: hacer, obras.

\section{Pictograma 515}

Igual a pictograma 210. Significa: misericordia.

\section{Pictograma 516}

Tres hileras verticales de cuatro circulitos, más otra únicamente con dos. Su significado es: catorce.

\section{Pictograma 517}

Igual a pictograma 286. Significa: siete.

\section{Pictograma 518}

Igual a pictograma 4. El significado en esa ocasión era "muestra", pero parece aconsejable, por el sentido del formulario, que en las obras de misericordia se le dé el significado de: necesita.

Es preciso advertir que este significado ("necesita") tampoco desentona absolutamente en el contexto del pictograma 4.

\section{Pictograma 519}

Parecido al pictograma 464, una figura, que recuerda vagamente el aspecto humano, pero a la que intencionadamente se dibuja de otra forma, tiene hasta la cintura la misma representación que el pictograma aludido, pero la parte inferior está recubierta de un vestido largo elaborado con un tejido fruncido. Su significado, por el sentido del formulario, y por comparación con otros pictogramas, es: cuerpo. 


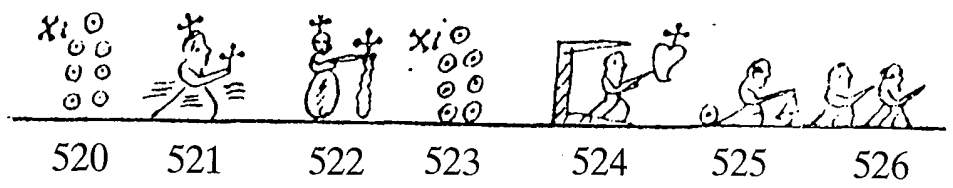

\section{Pictograma 520}

Igual a pictograma 286. Significa: siete.

\section{Pictograma 521}

Prácticamente igual a pictograma 4 y al más próximo pictograma 518; hay, sin embargo, una diferencia porque a un lado y otro de la figura, así como también en el centro aparecen grupos de tres rayas horizontales. Esta modificación pictográfica parece aconsejar que el significado que mejor cuadra a este pictograma en las ocasiones que aparece sea: consecuencias buenas.

\section{Pictograma 522}

Igual a pictograma 464. Significa: alma.

\section{Pictograma 523}

Igual a pictograma 286. Significa: siete.

\section{Pictograma 524}

Casi igual a pictograma 17, la persona introducida en las esquematizadas fauces infernales está apuntando a un corazón con un remate de cruz en la parte superior, que aparece dibujado en la parte superior derecha del pictograma. Su significado resulta un tanto ambiguo, ya que el sentido que el contexto aconseja sería: librar al cuerpo.

Sin embargo, en el pictograma 549 aparece idéntico dibujo, y ahí estaría recomendada la idea de "liberar al alma", puesto que comienzan las obras de misericordia espirituales. En este caso, al comenzar la obras de misericordia corporales, parece que el significado adecuado es el apuntado antes.

\section{Pictograma 525}

Igual a pictograma 13 . En este pictograma 13 el sentido sería el de "entonces"; aquí hay un notable margen de duda de que tal sentido sea el adecuado. Por eso, ensayando otro posible sentido, parece que podría significar: son éstas.

Esta interpretación tiene en su contra el que cuando ha aparecido esta idea (pictogramas 256,260 ) se ha expresado gráficamente de otra forma.

\section{Pictograma 526}

Igual a pictograma 263. Significa: la primera. 


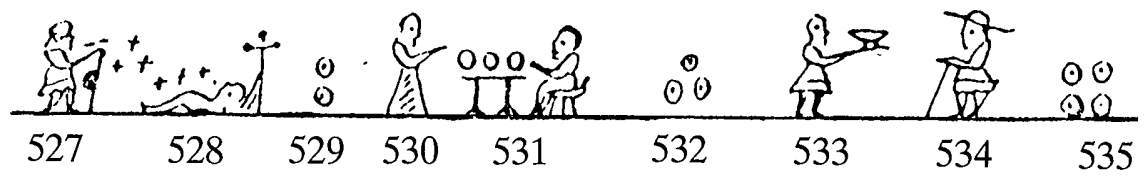

\section{Pictograma 527}

Una persona, con bastón, en actitud de caminar. Su significado es: visitar.

\section{Pictograma 528}

Igual a la segunda parte del pictograma 368 , aquí se aprecia mejor sobre el enfermo tumbado una serie de pequeñas cruces. Su significado es: enfermo.

\section{Pictograma 529}

Igual a pictograma 269. Significa: la segunda.

\section{Pictograma 530 y pictograma 531}

He dudado si numerarlos como un sólo pictograma o como dos; al final he optado por esta segunda solución, por seguir el paralelismo con los pictogramas 533 y 534, en que más claramente aparecen separados.

El pictograma 530 presenta a una persona con vestido largo, y el brazo extendido, en actitud de dar. Está dando, en el pictograma 531, una serie de tres panes (?) representados por sendos círculos, que aparecen en vertical encima de una mesa, a la cual se encuentra sentado otro personaje que mira hacia el del pictograma 530. El significado conjunto de ambos es: dar comida al hambriento.

\section{Pictograma 532}

Igual a pictograma 274. Significa: la tercera.

\section{Pictograma 533}

Una persona, con vestido corto, sostiene en sus manos una gran copa, que ofrece al personaje del pictograma siguiente.

\section{Pictograma 534}

Un personaje con sombrero y bastón mira hacia el pictograma anterior. El sentido conjunto de ambos es: dar bebida al sediento.

\section{Pictograma 535}

Igual a pictograma 278. Significa: la cuarta. 


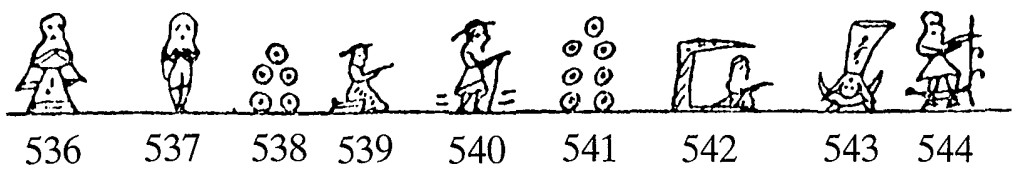

\section{Pictograma 536}

Una figura, sin rasgos expresivos en el rostro, aparece abundantemente vestida (túnica hasta los pies, largas mangas que caen por debajo de la altura de las manos, esclavina). Su sentido es: vestir.

\section{Pictograma 537}

En contraste con el pictograma anterior, una figura aparece desnuda, con una expresión triste. Su sentido es: al desnudo.

\section{Pictograma 538}

Igual a pictograma 282. Significa: la quinta.

\section{Pictograma 539}

Parecido al pictograma 213, una persona está sentada, pero carece del signo de la cruz en su mano, cosa que aparecía en 213. Su sentido es: acoger.

\section{Pictograma 540}

Igual a pictograma 217. Significa: desterrado. Podría significar también: viajero.

\section{Pictograma 541}

Igual a pictograma 286. Significa: la séptima.

Es evidente que el tlacuilo cometió un error, porque la numeración de las obras de misericordia reclama que aquí vaya "la sexta", máxime cuando la séptima aparece en el pictograma 545. Supliendo, pues, dicho error, el significado real que hay que atribuirle es: la sexta.

\section{Pictograma 542}

Igual a pictograma 17. Significa: librar, redimir.

\section{Pictograma 543}

Igual a pictograma 112. Significa: caer.

\section{Pictograma 544}

Igual a pictograma 504. Significa: prisión. 


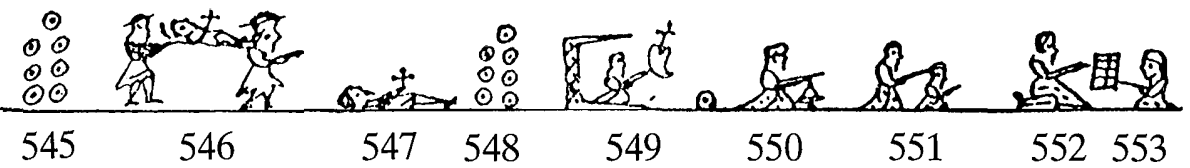

Pictograma 545

Igual a pictograma 286. Significa: la séptima.

\section{Pictograma 546}

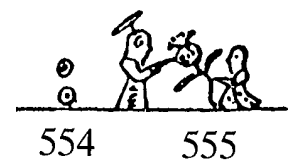

Dos personas portan sobre sus hombres unas parihuelas sobre las cuales va un cadaver. Su sentido es: enterrar.

\section{Pictograma 547}

Igual a pictograma 141. Significa: muerto.

\section{Pictograma 548}

Igual a pictograma 286. Significa: las siete.

\section{Pictograma 549}

Igual a pictograma 524. Ya está apuntado en este lugar que el significado que parece corresponderle, a pesar de la igualdad de las representaciones pictográficas, es: liberar al alma.

\section{Pictograma 550}

Igual a pictograma 525, con la modificación de significado allí señalada: son éstas.

\section{Pictograma 551}

Igual a pictograma 263. Significa: la primera.

\section{Pictograma 552 y pictograma 553}

El pictograma 552 es igual al pictograma 73. Está seguido del pictograma 553, en el que una persona acurrucada, apunta con su mano estilizada al libro que la del pictograma anterior le está presentando. El conjunto de ambos pictogramas significa: enseñar al ignorante.

\section{Pictograma 554}

Igual a pictograma 269. Significa: la segunda.

\section{Pictograma 555}

Igual a pictograma 496. Significa: premiar. 


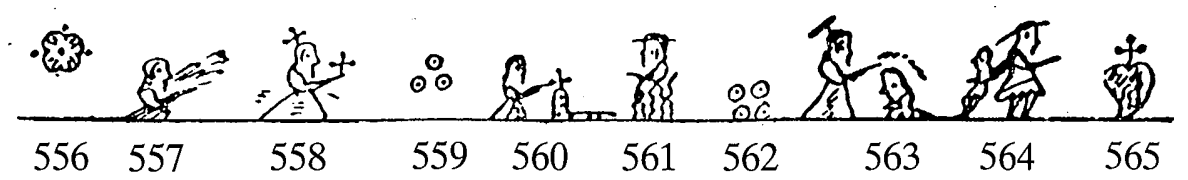

Pictograma 556

Igual a pictograma 80 . Significa: provechosas.

\section{Pictograma 557}

Igual a pictograma 43. Significa: palabras, consejos.

\section{Pictograma 558}

Igual a pictograma 521. Significa: consecuencias buenas.

\section{Pictograma 559}

Igual a pictograma 274. Significa: la tercera.

\section{Pictograma 560}

Una persona está apuntando con su mano estilizada a un montículo (?) alargado hacia la derecha, del que parece sobresalir una cruz. Hay que deducir su posible sentido del formulario de las obras de misericordia. Este sería el de: corregir.

\section{Pictograma 561}

Una persona en pie, con sombrero, aparece desde el tronco hasta el suelo dibujada por medio de unas líneas ondulantes. Su significado parece claro: errado.

\section{Pictograma 562}

Igual a pictograma 278. Significa: la cuarta.

\section{Pictograma 563}

Semejante al pictograma 105, aunque se haya invertido el orden de los personajes, y ninguno aparezca con rasgos divinos. Su sentido es: perdonar.

\section{Pictograma 564}

Dos personas aparece de espaldas la una a la otra, con un trazo que las vincula. Su significado es: injurias.

\section{Pictograma 565}

Igual a pictograma 8, pero a diferencia de aquél, éste aparece sombreado en el interior del dibujo. Significa: de mal corazón. 


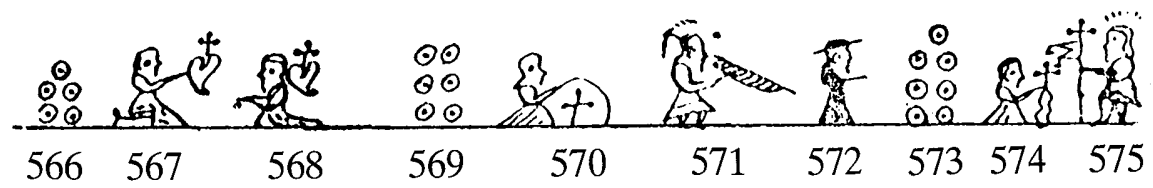

Pictograma 566

Igual a pictograma 282. Significa: la quinta.

\section{Pictograma 567}

Una persona sentada tiene en sus manos un corazón, rematado, como suele ser habitual, con una cruz. Su significado es: consolar.

\section{Pictograma 568}

Una persona arrodillada mira hacia la del pictograma anterior; a sus espaldas tiene un corazón, igualmente rematado con cruz. Su significado es: triste.

\section{Pictograma 569}

Igual a pictograma 284. Significa: la sexta.

\section{Pictograma 570}

Igual a pictograma 273. Significa: respetar.

\section{Pictograma 571}

Parecido al pictograma 203, un personaje con rasgos divinos (aureola), tiene en sus manos una palma. Su significado podría ser: (por) Dios la vida.

\section{Pictograma 572}

Igual a pictograma 204. Significa: prójimo.

\section{Pictograma 573}

Igual a pictograma 286. Significa: la séptima.

\section{Pictograma 574}

Igual a pictograma 3. Significa, conforme a uno de los posibles significados (ver pictograma 243): rogar.

\section{Pictograma 575}

Igual a pictograma 27; la representación está vuelta hacia la izquierda, para dirigirse al personaje del pictograma anterior. Significa: Dios. 


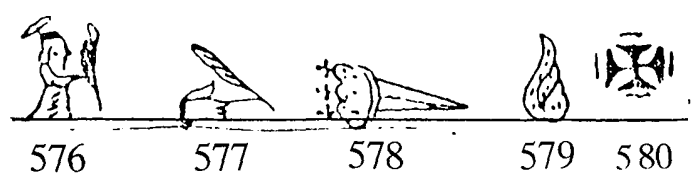

\section{Pictograma 576}

Igual a pictograma 203. Significa: vivos.

Al llegar a la última banda ocupada por las obras de misericordia, se invierte el sentido de la lectura, lo que indica una pequeña flecha en la parte extrema izquierda de este pictograma.

\section{Pictograma 577}

Igual a pictograma 19. Significa: y también.

\section{Pictograma 578}

Igual a pictograma 178. Significa: muertos.

\section{Pictograma 579}

Igual a pictograma 50. Significa: (se) haga.

\section{Pictograma 580}

Igual a pictograma 118. Significa: Jesús.

Con las dudas señaladas, y con el error de numeración detectado, el sentido descifrados de las obras de misericordia es éste: Las obras de misericordia (son) catorce: siete (que) muestra (o necesita) el cuerpo; (y) siete consecuencias buenas (para) el alma.

Las siete (que) liberan el cuerpo (?) son éstas (?): la primera, visitar a los enfermos; la segunda, dar comida al hambriento; la tercera, dar bebida al sediento; la cuarta, vestir al desnudo; la quinta, acoger al viajero; la sexta (?) liberar al (que) cayó en prisión; la séptima, enterrar a los muertos.

Las siete (que) liberan el alma (?) son éstas(?): la primera, enseñar al ignorante; la segunda, premiar (con) provechosas palabras de consecuencias buenas; la tercera, corregir al errado; la cuarta, perdonar las injurias (que salen) del mal corazón; la quinta, consolar al triste; la sexta, respetar por Dios la vida del prójimo; la séptima, rogar a Dios (por) los vivos y también (por) los muertos. (Así) se haga, Jesús. 


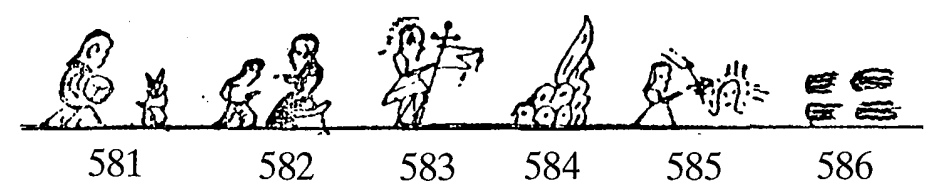

\title{
DUODECIMA PARTE
}

\author{
YO PECADOR
}

El texto del "Yo, pecador" no suele ofrecer especiales dificultades en los catecismos pictográficos, tanto por el hecho de estár constituído en gran manera por una serie de nombres en sucesión, como por el de la iteración de la serie en la segunda parte de la oración.

\section{Pictograma 581}

Pictograma compuesto de una figura poco precisa en la que parece que el personaje se está señalando a sí mismo con la mano; a su lado, se reproduce el pictograma 18, representación del pecado. Su sentido es: yo, pecador.

\section{Pictograma 582}

Igual a pictograma 327. Significa: confieso

\section{Pictograma 583}

Igual a pictograma 27. Significa: Dios.

\section{Pictograma 584}

Igual a pictograma 485. Significa: todohacedor.

\section{Pictograma 585}

Un personaje, en primer término, sostiene una especie de rama que se bifurca en la parte superior; parece que hubiera que asignarle el sentido de la preposición "a". En segundo lugar, aparece la representación del pictograma 124, que manifestaba el concepto de "divinidad", referido, en aquella ocasión a Dios. En cambio, en el transcurso de esta oración, dicho concepto o pictograma no se refiere a Dios, sino a algún santo, por lo cual parece que este es el significado más aconsejable: $a$ santa.

\section{Pictograma 586}

Igual a pictograma 204. Significa: siempre. 


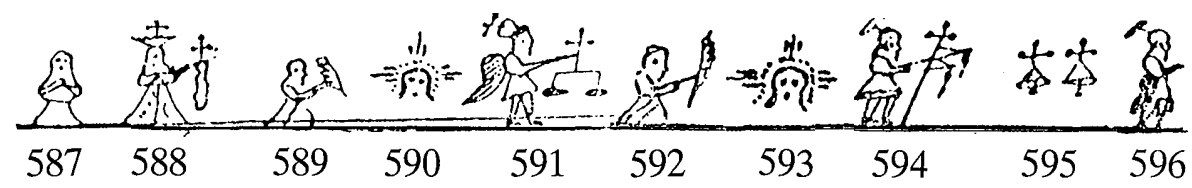

Pictograma 587

Igual a pictograma 447. Significa: virgen.

\section{Pictograma 588}

Igual a pictograma 209. Significa: María,

\section{Pictograma 589}

Podría estimarse una variante del pictograma 19, pues en lugar de aparecer la mano con una pluma, aparece toda la persona con una pluma. No parece que esto afecto a su significado: $y$ (también).

\section{Pictograma 590}

Igual a pictograma 585. Significa: san.

\section{Pictograma 591}

Un personaje de índole angelical a juzgar por las alas a su espalda, tiene un sombrero troncocónico, rematado en una cruz; en su mano sostiene una balanza. Su significado es: Miguel, arcángel.

\section{Pictograma 592}

Igual a pictograma 589. Significa: $y$.

\section{Pictograma 593}

Igual a pictograma 585. Significa: san.

\section{Pictograma 594}

Igual a pictograma 27, pero con una variante importante, puesto que los atributos divinos de la aureola de rayos han sido substituídos por una simple corona. Su significa cambia, y, en consonancia con el avance la oración, es: Juan Bautista.

\section{Pictograma 595}

Igual a pictograma 198. Significa: santos.

\section{Pictograma 596}

Una persona, con corona, en pie, pero sin ningún otro rasgo distintivo. Su significado ha de ser: Apóstoles. 


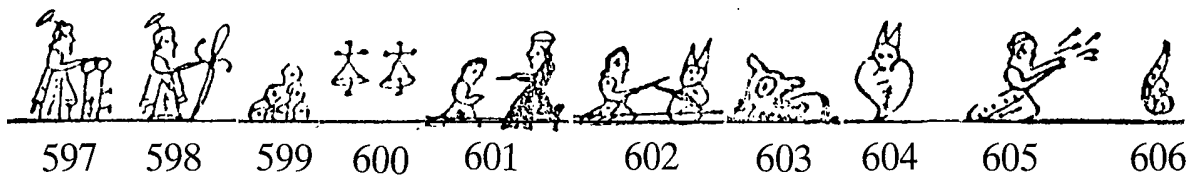

\section{Pictograma 597}

Una persona parecida a la del pictograma anterior tiene en la mano dos gigantescas llaves, que llegan hasta el suelo. Su significado es: Pedro.

\section{Pictograma 598}

Similar al pictograma anterior, cambia el atributo, que en esta ocasión es una enorme espada, que le sobrepasa en estatura (También puede verse el tamaño descomunal de la espada del pictograma 283). Su sentido es: Pablo.

\section{Pictograma 599}

Igual a pictograma 1. Significa: todos.

\section{Pictograma 600}

Igual a pictograma 198. Significa: santos.

\section{Pictograma 601}

Igual a pictograma 327. Sin embargo, aquí parece aconsejable, siguiendo el hilo de la oración que el significado no se ciña a "confesar", sino que signifique: a tí, padre.

\section{Pictograma 602}

Parecido a pictograma 110, pero invirtiendo el orden aparece en primer lugar la persona, que con su mano llega a tocar la representación del pecado. Su significado es: yo pequé.

\section{Pictograma 603}

Igual a pictograma 22. Significa: malos.

\section{Pictograma 604}

Igual a pictograma 36. Significa: pensamientos.

\section{Pictograma 605}

Igual a pictograma 43. Significa: palabras.

\section{Pictograma 606}

Igual a pictograma 50. Significa: obras. 


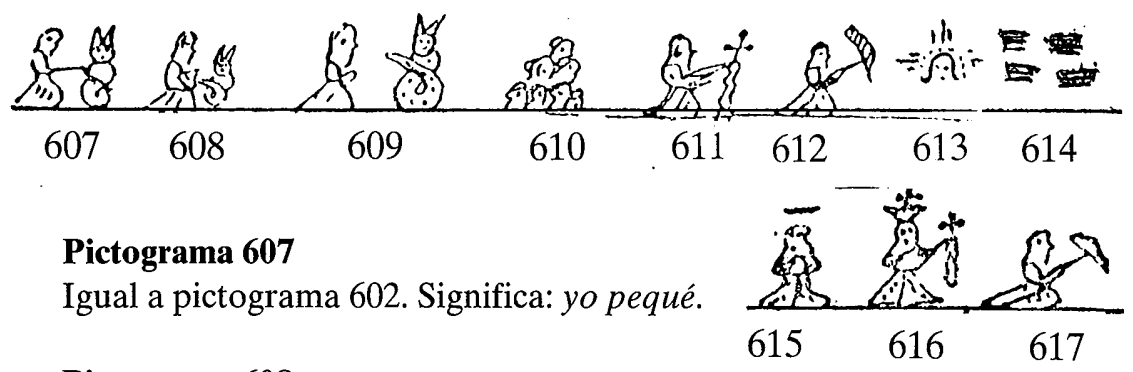

\section{Pictograma 608}

Igual a pictograma 602. Significa: yo pequé.

\section{Pictograma 609}

Igual a pictograma 602, con la particularidad del mayor tamaño de las dos figuras. Con ello, su significado se modifica ligeramente: yo pequé mucho.

\section{Pictograma 610}

Igual a pictograma 1 . Significa: todo.

Sin embargo, aquí no encaja semejante significado, y la propuesta, con arreglo al sentido de la oración es: por eso.

\section{Pictograma 611}

Igual a pictograma 573. Significa, también en esta ocasión: ruego.

\section{Pictograma 612}

Igual a pictograma 589. El contexto de la oración no aconseja aceptar el sentido de la conjunción "y", sino que su significado sea: que.

\section{Pictograma 613}

Igual a pictograma 590. Significa: santa.

\section{Pictograma 614}

Igual a pictograma 204. Significa: siempre

\section{Pictograma 615}

Igual a pictograma 447. Significa: virgen.

\section{Pictograma 616}

Igual a pictograma 209. Significa: María.

\section{Pictograma 617}

Igual a pictograma 612. Significa: que. 


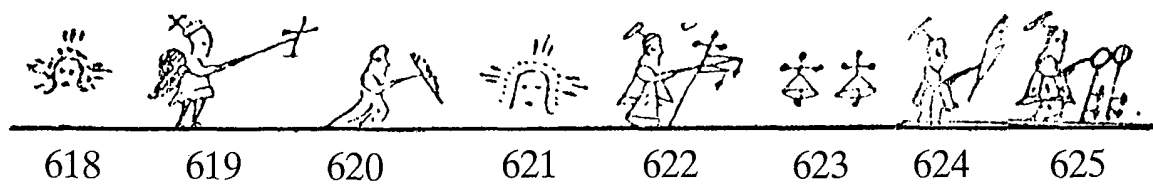

Pictograma 618

Igual a pictograma 585. Significa: san.

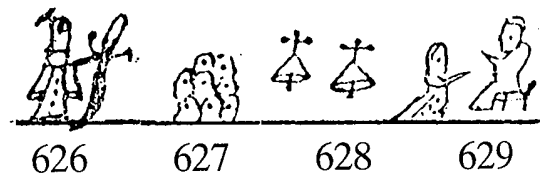

Pictograma 619

Igual a pictograma 591. Significa: Miguel, arcángel.

Pictograma 620

Igual a pictograma 612. Significa: que.

Pictograma 621

Igual a pictograma 585. Significa: san.

Pictograma 622

Igual a pictograma 594. Significa: Juan Bautista.

\section{Pictograma 623}

Igual a pictograma 198. Significa: santos.

\section{Pictograma 624}

Igual a pictograma 596. Significa: apóstoles.

\section{Pictograma 625}

Igual a pictograma 597. Significa: Pedro.

\section{Pictograma 626}

Igual a pictograma 598. Significa: Pablo.

\section{Pictograma 627}

Igual a pictograma 1. Significa: todos.

Pictograma 628

Igual a pictograma 198. Significa: santos.

\section{Pictograma 629}

Igual a pictograma 601. Significa: a tí, padre. 


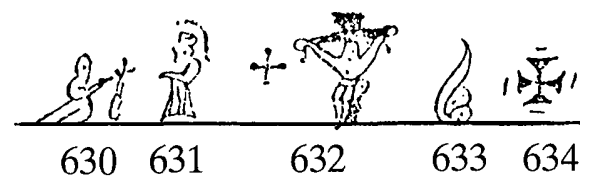

\section{Pictograma 630}

Igual a pictograma 573. Significa: rueguen.

\section{Pictograma 631}

Igual a pictograma 27. Significa: Dios.

\section{Pictograma 632}

Igual a pictograma 11. Significa: Jesucristo.

\section{Pictograma 633}

Igual a pictograma 50. Significa: (se) haga.

\section{Pictograma 634}

Igual a pictograma 118. Significa: Jesús.

Al final de la oración, recapitulando, se aprecia que son pocos los pictogramas nuevos, los estrictamente necesarios para manifestar los nuevos conceptos de determinados santos. En cambio, sí se observa un aconsejable cambio de significado con relación a pictogramas iguales aparecidos con anterioridad, en función del sentido de la oración. Esta queda como sigue: Yo, pecador, confieso a Dios todohacedor, a la santa siempre virgen María, y a San Miguel arcángel y san Juan Bautista, los santos apóstoles Pedro (y) Pablo, todos los santos y a tí, padre: yo pequé (con) malos pensamientos, palabras y obras yo pequé, yo pequé, yo pequé mucho. Por eso (?) ruego que (?) santa siempre virgen María, que san Miguel arcángel, que san Juan Bautista, los santos apóstoles Pedro (y) Pablos, todos los santos, y tú, padre, rueguen a Dios (y) a Jesucristo. (Así) se haga, Jesús. 


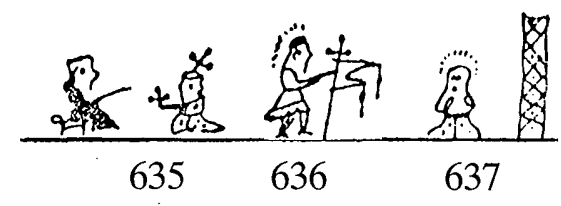

\section{DECIMOTERCERA PARTE}

\section{PREGUNTAS Y RESPUESTAS}

Ya indiqué en la introducción que aparecen en esta parte una serie de preguntas relativas a la doctrina cristiana. El título asignado por Nicolás León a este apartado no es exacto, ya que las preguntas, como suceden en otros catecismos breves, se ciñen a unos cuantos aspectos fundamentales en cuanto a las creencias (temas dogmáticos), más alguna otra pregunta estimada como fundamental relativa a la debida recepción y creencia sobre algunos sacramentos (temas sacramentales). El resto de los posibles temas están ausentes de esta parte.

Son concretamente ventitrés preguntas, unas breves y otras más largas, pero ninguna excesivamente amplia.

Están perfectamente precisados los límites de cada pregunta y de cada respuesta, de manera que no es preciso hacer cábalas sobre su correspondiente extensión: una trazo vertical ancho, con una línea interior ondulante adornada de puntos (salvo algunos casos en que se modifica el adorno) marca el final de la respectiva pregunta o respuesta. Se trata, como ya está indicado, del Catecismo de Bartolomé Castaño, aunque no se mencione su nombre.

\section{Pregunta 1}

\section{Pictograma 635}

Parecido a pictograma 327, el que se supone sacerdote (por el color obscuro del vestido) pregunta a otra persona arrodillada ante él. Su significado hay que deducirlo del conjunto de la pregunta: Cuántos.

\section{Pictograma 636}

Igual a pictograma 27. Significa: $\operatorname{Dios}(e s)$.

\section{Pictograma 637}

Igual a pictograma 87. Significa: están o hay. 


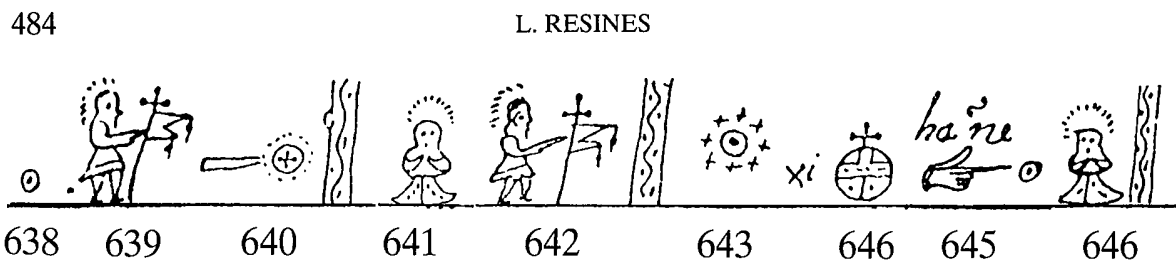

\section{Pictograma 638}

Un círculo, con un punto central. Su sentido es: un único.

\section{Pictograma 639}

Igual a pictograma 27. Significa: Dios.

\section{Pictograma 640}

Igual a pictograma 2. Significa: verdadero.

$P$. ¿Cuántos dioses hay? R. Un único Dios verdadero.

\section{Pregunta 2}

\section{Pictograma 641}

Igual a pictograma 87. Significa: está.

\section{Pictograma 642}

Igual a pictograma 27. Significa: Dios.

\section{Pictograma 643}

Igual a pictograma 88 . Significa: cielo.

\section{Pictograma 644}

Igual a pictograma 97 . Significa: tierra.

Entre estos dos pictogramas aparece escrita la sílaba "xi".

\section{Pictograma 645}

Igual a pictograma 68 , la mano está designando a un círculo como el del pictograma 638. En la parte superior aparece escrito "ha ne". Significa: este único.

\section{Pictograma 646}

Igual a pictograma 87. Significa: está.

P. ¿(Dónde) está Dios? R. (En) el cielo (y) la tierra este único está. 


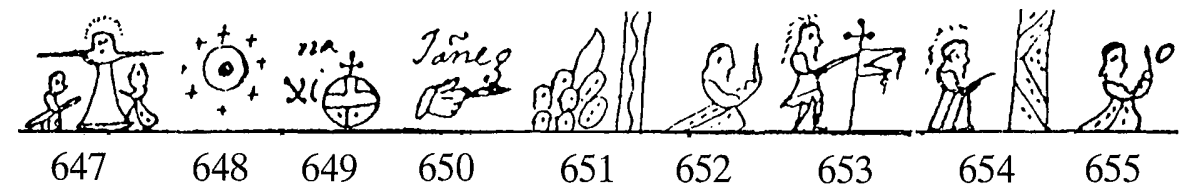

\section{Pregunta 3}

\section{Pictograma 647}

Igual a pictograma 150. Significa: creador.

\section{Pictograma 648}

Igual a pictograma 88 . Significa: cielo.

\section{Pictograma 649}

Igual a pictograma 97. Significa: tierra.

Entre ambos pictogramas aparece la inscripción "na xi".

\section{Pictograma 650}

Igual a pictograma 68, con la leyenda "Jañeg". Podría significar: es, o es también.

\section{Pictograma 651}

Igual a pictograma 485. Significa: todohacedor.

\section{Pictograma 652}

Igual a pictograma 16. Significa: por, porque.

\section{Pictograma 653}

Igual a pictograma 27. Significa: Dios.

\section{Pictograma 654}

Igual a pictograma 57. Significa: Señor.

$P$. ¿El creador del cielo (y) tierra es también todohacedor? R. (Sí), porque (es) Dios Señor.

\section{Pregunta 4}

\section{Pictograma 655}

Casi igual a pictograma 16, la persona tiene antes sí un pequeño círculo. Su significado es: quién es. 


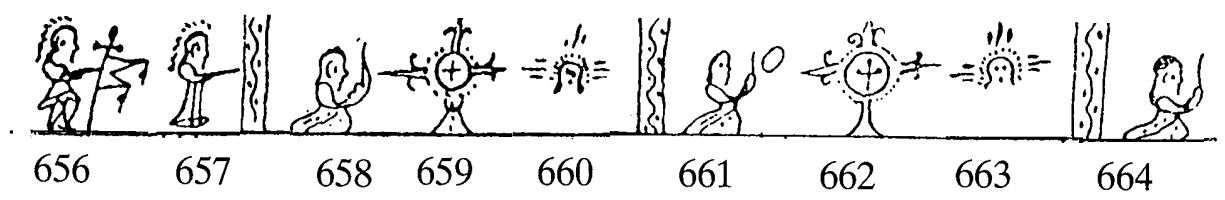

Pictograma 656

Igual a pictograma 27. Significa: Dios.

\section{Pictograma 657}

Igual a pictograma 57. Significa: Señor.

\section{Pictograma 658}

Igual a pictograma 16. Significa: por, porque.

En otras ocasiones (por ejemplo, en el pictograma 652) parecía explícito el sentido de "por" e implícito el de "es". En esta ocasión, así como en la pregunta siguiente, parece que encaja mejor dejar explícito el verbo.

\section{Pictograma 659}

Igual a pictograma 79. Significa, en esta ocasión, deducido por el sentido de la pregunta: santísima.

\section{Pictograma 660}

Igual a pictograma 124. Significa: divinidad, o también, cuadra mejor el sentido de Trinidad.

P. ¿Quién es Dios Señor? R. Es la santisima Trinidad.

\section{Pregunta 5}

\section{Pictograma 661}

Igual a pictograma 665. Significa: quién es.

\section{Pictograma 662}

Igual a pictograma 659. Significa: santísima.

\section{Pictograma 663}

Igual a pictograma 660. Significa: Trinidad.

\section{Pictograma 664}

Igual a pictograma 658. Significa: es. 


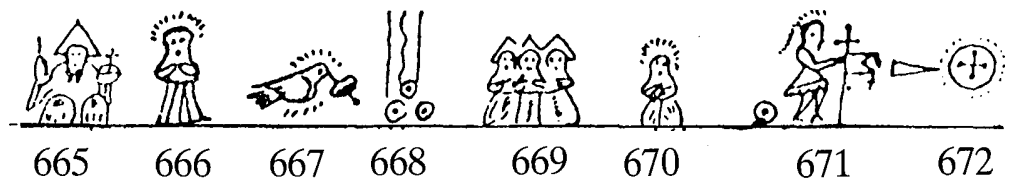

\section{Pictograma 665}

Igual a pictograma 61. Significa: Padre.

\section{Pictograma 666}

Igual a pictograma 62. Significa: Hijo.

\section{Pictograma 667}

Igual a pictograma 63. Significa: Espíritu Santo.

\section{Pictograma 668}

Casi igual a pictograma 274, aparecen tres círculos; por encima parece que apunta un fallo del tlacuilo, que empezó a señalar el final de la respuesta, haciendo el trazo ancho y la línea ondulada interior, pero no llegó a concluirlo, porque había que completar la respuesta. Significa: tres.

\section{Pictograma 669}

Parecido a pictograma 197, con una expresiva diferencia, pues en 197 sobre cada una de las cabezas hay una cruz, mientras que en éste, sobre cada una de las cabezas hay un triángulo (atributo divino que aparece en pictograma 61, y mucho más claramente en pictograma 665. Significa: tres Personas iguales.

\section{Pictograma 670}

Igual a pictograma 87. Significa: está, hay.

\section{Pictograma 671}

Igual a pictograma 27, si bien está precedido del círculo que aparecía en el pictograma 638 y 645. Significa: un único Dios.

\section{Pictograma 672}

Igual a pictograma 2. Significa: verdadero.

P. ¿Quién es la santísima Trinidad? R. Es Padre, Hijo (y) Espíritu Santo, tres personas iguales, (pero) un único Dios verdadero. 


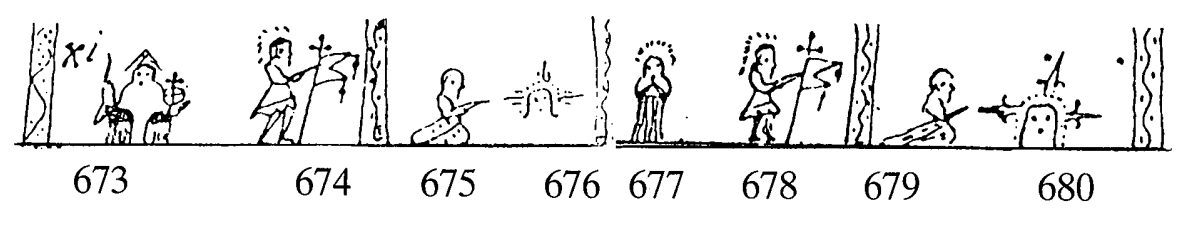

Pregunta 6

\section{Pictograma 673}

Igual a pictograma 61. Significa: Padre.

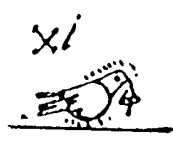

681

\section{Pictograma 674}

Igual a pictograma 27. Significa: Dios.

\section{Pictograma 675}

Parecido a pictograma 16, el personaje arrodillado tiene su estilizada mano extendida, en lugar de tenerla en posición vertical. Significa: sí.

\section{Pictograma 676}

Igual a pictograma 124. Significa: divinidad.

P. ¿El Padre (es) Dios? R. Sí, (es) divinidad.

\section{Pregunta 7}

\section{Pictograma 677}

Igual a pictograma 62. Significa: Hijo.

\section{Pictograma 678}

Igual a pictograma 27. Significa: Dios.

\section{Pictograma 679}

Igual a pictograma 675. Significa: sí.

\section{Pictograma 680}

Igual a pictograma 124. Significa: divinidad. $P$. ¿El Hijo (es) Dios? R. Sí, (es) divinidad.

\section{Pregunta 8}

\section{Pictograma 681}

Igual a pictograma 63. Significa: Espíritu Santo. 


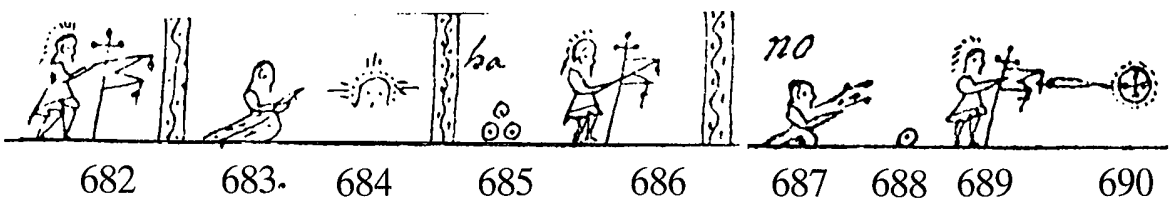

\section{Pictograma 682}

Igual a pictograma 27. Significa: Dios.

\section{Pictograma 683}

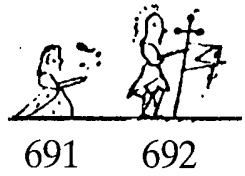

Igual a pictograma 675. Significa: sí.

\section{Pictograma 684}

Igual a pictograma 124. Significa: divinidad.

P. ¿El Espíritu Santo (es) Dios? R. Sí, (es) divinidad.

\section{Pregunta 9}

\section{Pictograma 685}

Igual a pictograma 274. Significa: tres.

\section{Pictograma 686}

Igual a pictograma 27. Significa: Dioses.

\section{Pictograma 687}

Igual a pictograma 51. Sin embargo, el significado que marca el contexto de la pregunta exige otro sentido, que está expresado en una inscripción aneja en la parte superior izquierda del pictograma "no": no.

\section{Pictograma 688}

Igual a pictograma 638. Significa: un único.

\section{Pictograma 689}

Igual a pictograma 27. Significa: Dios.

\section{Pictograma 690}

Igual a pictograma 2. Significa: verdadero.

\section{Pictograma 691}

Igual a pictograma 16. Significa: por, porque.

\section{Pictograma 692}

Igual a pictograma 27. Significa: Dios. 


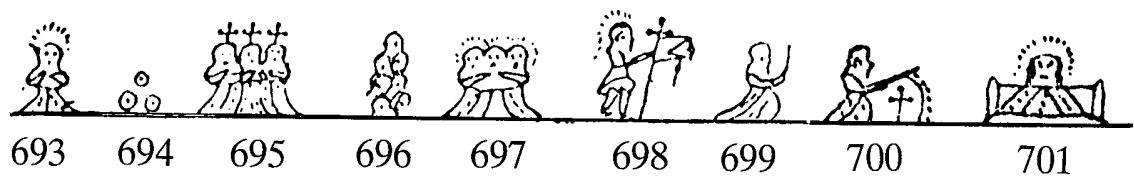

Pictograma 693

Igual a pictograma 87. Significa: hay, está.

\section{Pictograma 694}

Igual a pictograma 274. Significa: tres.

\section{Pictograma 695}

Igual a pictograma 197. Significa: unión, comunión.

\section{Pictograma 696}

Igual a pictograma 1 . Significa: todas.

\section{Pictograma 697}

Igual a pictograma 669 , cambiando que al atributo divino de las coronas triangulares ha sido substituído por una triple aureola. Significa: personas divinas.

\section{Pictograma 698}

Igual a pictograma 27. Significa: Dios.

\section{Pictograma 699}

Igual a pictograma 652. Significa: porque es.

\section{Pictograma 700}

Igual a pictograma 273. Significa: respetar. respeto.

Podría, quizá, encajar el sentido de "misterio", para tratar de dotar de lógica a la última parte de la respuesta a este pregunta.

\section{Pictograma 701}

Un personaje parecido al del pictograma 27, aparece con aureola de rayos; a un lado y otro hay dos pequeños postes o columnas y una línea que va del uno al otro. No he encontrado un significado que encaje adecuadamente con este pictograma, que podría ser: está.

La última parte de la respuesta, desde el pictograma 699 al 703, queda imprecisa respecto a la primera parte, con un significado neto. 


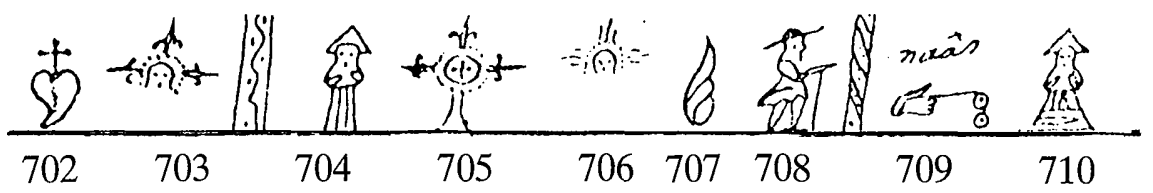

\section{Pictograma 702}

Igual a pictógrama 8 . Significa: corazón.

\section{Pictograma 703}

Igual a pictograma 124. Significa: divinidad.

$P . ~ ¿(S o n)$ tres dioses? $R$. No, un único Dios verdadero, porque en Dios hay tres en unión (de) todas las personas divinas; porque es respeto (o misterio) lo que está en el corazón de la divinidad.

\section{Pregunta 10}

\section{Pictograma 704}

Similar a pictograma 669, se representa una sola de las personas divinas, reconocible por el atributo de la corona triangular. Su sentido es: persona divina.

\section{Pictograma 705}

Igual a pictograma 659. Significa: santísima.

\section{Pictograma 706}

Igual a pictograma 660. Significa: Trinidad.

\section{Pictograma 707}

Igual a pictograma 50. Significa: (se) hizo.

\section{Pictograma 708}

Igual a pictograma 160. Significa: hombre.

\section{Pictograma 709}

Parecido a pictograma 645, la mano apunta a dos círculos; en la parte superior del pictograma aparece la inscripción "naas". Su significado es: esta segunda.

\section{Pictograma 710}

Igual a pictograma 704. Significa: persona divina. 


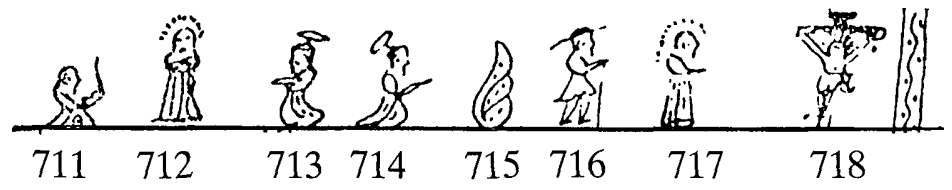

\section{Pictograma 711}

Igual a pictograma 16. Significa: por, porque (es).

\section{Pictograma 712}

Igual a pictograma 62. Significa: Hijo.

\section{Pictograma 713}

Un personaje con corona está semiarrodillado apuntando con su mano a la representación del pictograma anterior. No he encontrado un sentido que se adecúe debidamente a esta representación .

\section{Pictograma 714}

Igual a pictograma anterior, 713, pero invertido su sentido. Puede significar: quien.

En caso de que se atribuyese el sentido de "quien" al pictograma anterior, sería éste el que quedaría desprovisto de un significado claro. Me ha parecido que a éste, en el mismo sentido habitual del desarrollo de la escritura pictográfica, podría cuadrar mejor dicho significado, con preferencia al pictograma anterior, con el sentido invertido.

\section{Pictograma 715}

Igual a pictograma 50. Significa: hecho.

\section{Pictograma 716}

Igual a pictograma 160. Significa: hombre.

\section{Pictograma 717}

Igual a pictograma 57. Significa: Señor.

\section{Pictograma 718}

Igual a pictograma 11. Significa: Jesucristo.

$P$. ¿(Qué) persona divina de la santísima Trinidad se hizo hombre? $R$. Esta segunda persona divina que es el Hijo (...) quien hecho hombre (es) el Señor Jesucristo. 


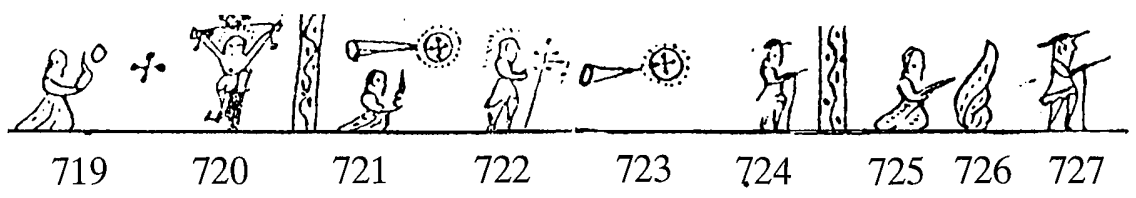

\section{Pregunta 11}

Pictograma 719

Igual a pictograma 655. Significa: quién es.

Pictograma 720

Igual a pictograma 11. Significa: Jesucristo.

\section{Pictograma 721}

Igual a pictograma 2. Significa: verdadero.

\section{Pictograma 722}

Igual a pictograma 27. Significa: Dios.

\section{Pictograma 723}

Igual a pictograma 2. Significa: verdadero.

\section{Pictograma 724}

Igual a pictograma 160. Significa: hombre.

$P$. ¿Quién es Jesucristo? R. Verdadero Dios (y) verdadero hombre.

\section{Pregunta 12}

\section{Pictograma 725}

Parecido a pictograma 16. Significa: cómo.

Puede observar la diferencia entre este pictograma y el pictograma 764, que sí es igual al pictograma 16 y que lleva a asignarle el sentido de "por qué". En cambio, en el presente, y a la vista de la respuesta completa, el sentido que más se adecúa es el de "cómo".

\section{Pictograma 726}

Igual a pictograma 50. Significa: (se) hizo.

\section{Pictograma 727}

Igual a pictograma 160. Significa: hombre. 


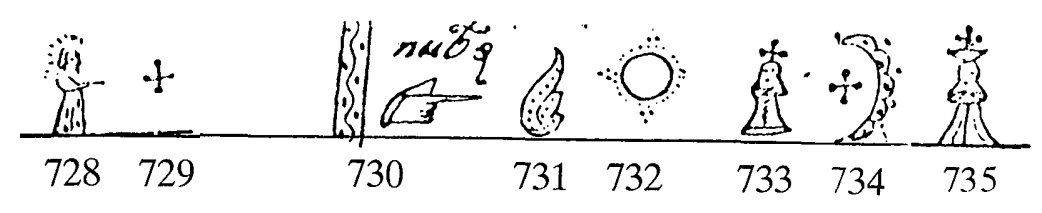

\section{Pictograma 728}

Igual a pictograma 57. Significa: Señor.

\section{Pictograma 729}

Igual a pictograma 118. Significa: Jesús.

Sin embargo no es difícil detectar que se ha producido un fallo en el presente pictograma, porque queda un espacio en blanco que tendría que haber sido ocupado por la representación de Jesús en la cruz, de manera que quedara completo el pictograma, que sería igual al pictograma 11. El autor ha dibujado la primera parte, y se ha olvidado de la segunda; sin embargo la pregunta anterior (pictograma 720) está centrada concretamente sobre "Jesucristo", y era lógico que en ésta sucediera lo mismo.

\section{Pictograma 730}

Igual a pictograma 68, con la inscripción "nubq", que aparece en pictograma 272. Significa: mandar.

\section{Pictograma 731}

Igual a pictograma 50. Significa: (se) hizo.

\section{Pictograma 732}

Un círculo grande rodeado de aureola de puntos, y además con adornos de otros tres puntos arriba, abajo, a derecha e izquierda. En pictograma 892 vuelve a aparecer, con el significado de pan eucarístico. De ahí el que en el presente pictograma se le pueda atribuir el significado de cuerpo, que encaja mejor que simplemente el de pan.

\section{Pictograma 733}

Igual a pictograma 87. Significa: está.

\section{Pictograma 734}

Igual a la segunda parte del pictograma 130. Significa: vientre.

\section{Pictograma 735}

Igual a pictograma 133. Significa: María. 


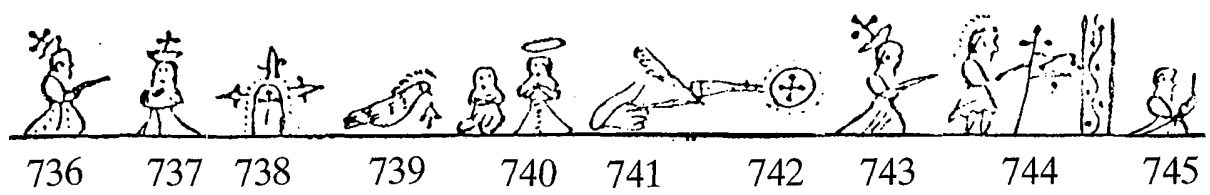

Pictograma 736

Igual a pictograma 132. Significa: santa.

Pictograma 737

Igual a pictograma 133. Significa: María.

Pictograma 738

Igual a pictograma 161. Significa: por obra.

\section{Pictograma 739}

Igual a pictograma 63. Significa: Espíritu Santo.

\section{Pictograma 740}

Pictograma compuesto de los pictogramas 87 (significa "está"), y 447 (significa "virgen"). Su sentido es: permaneció virgen.

\section{Pictograma 741}

Igual a pictograma 19. Significa: y también.

\section{Pictograma 742}

Igual a pictograma 2. Significa: verdadera.

\section{Pictograma 743}

Igual a pictograma 134. Significa: madre.

\section{Pictograma 744}

Igual a pictograma 27. Significa: Dios.

$P$. ¿Cómo se hizo hombre Jesucristo? R. Al mandar [el Espíritu Santo] (que) se hiciese (su) cuerpo, está (en) el vientre de María, santa María, (por) obra del Espíritu Santo, permanece virgen y también (es) verdadera madre de Dios.

\section{Pregunta 13}

\section{Pictograma 745}

Igual a pictograma 16. Significa: por, por qué. 


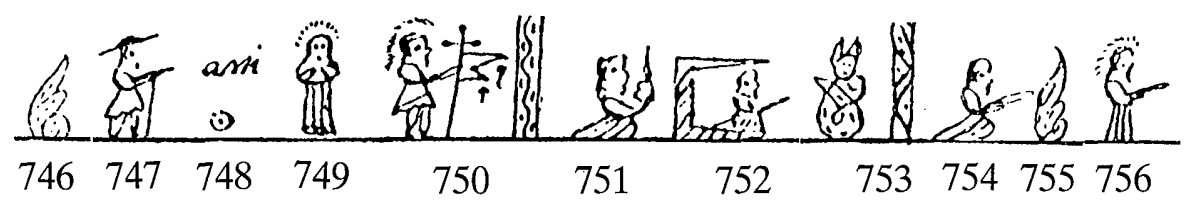

Pictograma 746

Igual a pictograma 50. Significa: (se) hizo.

\section{Pictograma 747}

Igual a pictograma 160. Significa: hombre.

\section{Pictograma 748}

Igual a pictograma 638. Significa: el único.

\section{Pictograma 749}

Igual a pictograma 63. Significa: Hijo.

\section{Pictograma 750}

Igual a pictograma 27. Significa: Dios.

\section{Pictograma 751}

Igual a pictograma 16. Significa: por, porque.

\section{Pictograma 752}

Igual a pictograma 17. Significa: liberar(nos).

\section{Pictograma 753}

Igual a pictograma 18. Significa: pecado.

$P$. ¿Por qué se hizo hombre el único Hijo de Dios? R. Por liberarnos del pecado.

\section{Pregunta 14}

\section{Pictograma 754}

Igual a pictograma 725. Significa: cómo.

\section{Pictograma 755}

Igual a pictograma 50. Significa: hizo.

Pictograma 756

Igual a pictograma 57. Significa: Señor. 


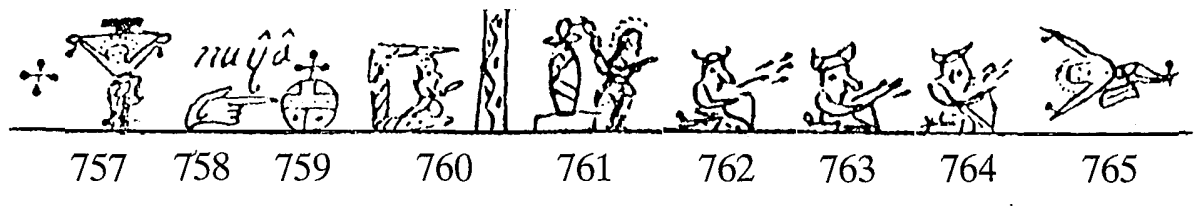

Pictograma 757

Igual a pictograma 11. Significa: Jesucristo.

\section{Pictograma 758}

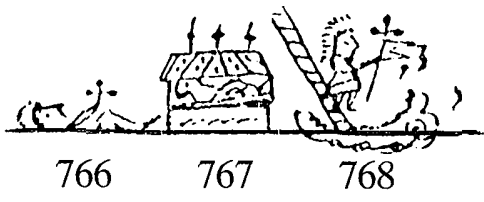

Igual a pictograma 68 ; además consta la inscripción "nuya". Significa: en esta.

\section{Pictograma 759}

Igual a pictograma 97. Significa: tierra.

\section{Pictograma 760}

Igual a pictograma 17. Significa: liberar(nos).

\section{Pictograma 761}

Igual a pictograma 167. Significa: pasión, padeció.

\section{Pictograma 762}

Igual a pictograma 168. Significa: (a) las órdenes.

\section{Pictograma 763}

Igual a pictograma 169. Significa: Poncio.

\section{Pictograma 764}

Igual a pictograma 170. Significa: Pilato.

\section{Pictograma 765}

Igual a pictograma 171. Significa: crucificado.

\section{Pictograma 766}

Igual a pictograma 172. Significa: muerto.

\section{Pictograma 767}

Igual a pictograma 173. Significa: sepultado.

\section{Pictograma 768}

Igual a pictograma 174. Significa: bajó al infierno. 


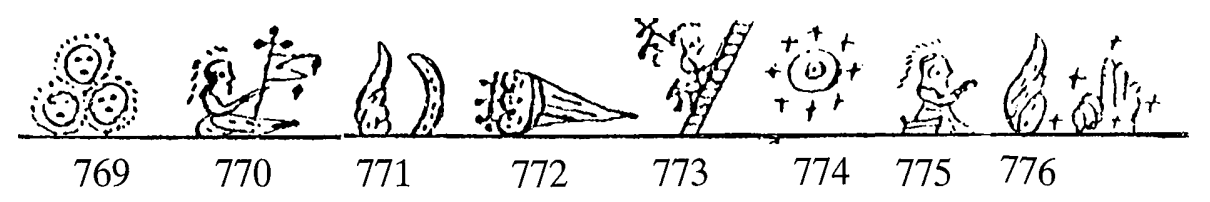

Pictograma 769

Igual a pictograma 175. Significa: al tercer día.

Pictograma 770

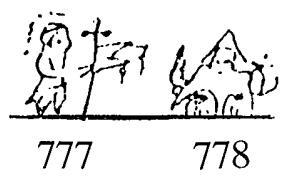

Igual a pictograma 176. Significa: resucitó.

Pictograma 771

Igual a pictograma 177. Significa: de entre.

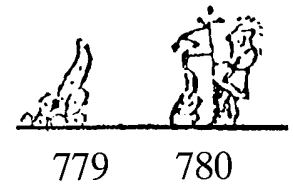

Pictograma 772

Igual a pictograma 178. Significa: muertos.

\section{Pictograma 773}

Igual a pictograma 179. Significa: subió.

\section{Pictograma 774}

Igual a pictograma 180. Significa: cielo.

\section{Pictograma 775}

Igual a pictograma 181. Significa: sentado.

\section{Pictograma 776}

Igual a pictograma 182. Significa: a la bendita mano derecha.

Pictograma 777

Igual a pictograma 183. Significa: Dios.

\section{Pictograma 778}

Igual a pictograma 184. Significa: Padre.

\section{Pictograma 779}

Igual a pictograma 185. Significa: todohacedor.

\section{Pictograma 780}

Igual a pictograma 186. Significa: desde allí vendrá. 


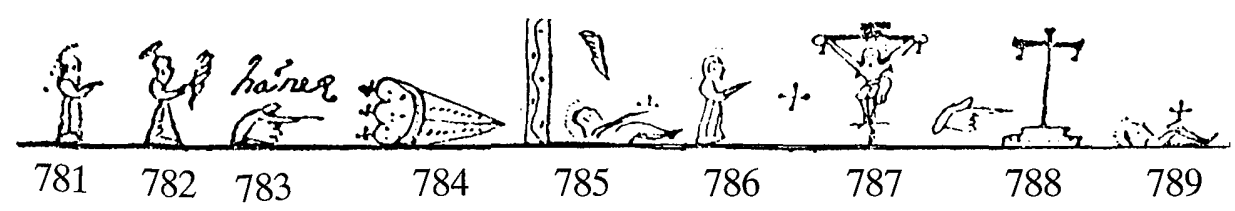

Pictograma 781

Igual a pictograma 188. Significa: juzgar.

Pictograma 782

Igual a pictograma 189. Significa: vivos.

\section{Pictograma 783}

Igual a pictograma 190. Significa: y también.

\section{Pictograma 784}

Igual a pictograma 191. Significa: muertos.

$P$. ¿Cómo hizo el Señor Jesucristo en esta tierra (para) liberarnos? $R$. Padeció a las órdenes de Poncio Pilato; (fue) crucificado, muerto (y) sepultado; bajó al infierno; al tercer día resucitó de entre los muertos; subió al cielo; (está) sentado a la bendita mano derecha de Dios Padre todohacedor; desde allí vendrá (a) juzgar (a) vivos y muertos.

\section{Pregunta 15}

\section{Pictograma 785}

Semejante al pictograma 15 , tiene el añadido en la parte superior izquierda del pictograma de una pluma similar a la del pictograma 19. $\mathrm{Su}$ sentido podría ser: $y$ al morir.

Pictograma 786

Igual a pictograma 57. Significa: Señor.

\section{Pictograma 787}

Igual a pictograma 11. Significa: Jesucristo.

\section{Pictograma 788}

Igual a pictograma 10. Significa: (en) la cruz.

\section{Pictograma 789}

Igual a pictograma 15. Significa: murió. 


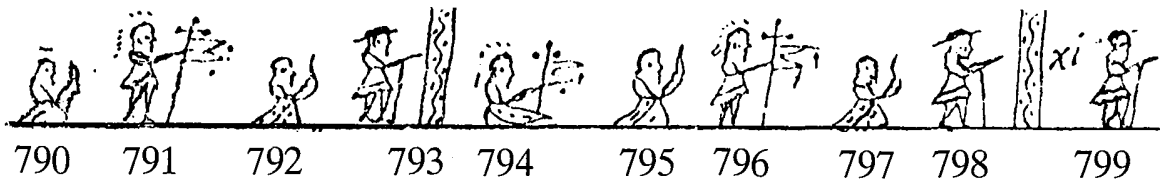

Pictograma 790

Igual a pictograma 16. Significa: porque. También podría interpretarse como: en cuanto.

\section{Pictograma 791}

Igual a pictograma 27. Significa: Dios.

\section{Pictograma 792}

Igual a pictograma 790. Significa: porque, o también en cuanto.

\section{Pictograma 793}

Igual a pictograma 160. Significa: hombre.

\section{Pictograma 794}

Igual a pictograma 176. Significa: resucitó.

\section{Pictograma 795}

Igual a pictograma 790. Significa: porque, o también en cuanto.

\section{Pictograma 796}

Igual a pictograma 27. Significa: Dios.

\section{Pictograma 797}

Igual a pictograma 790. Significa: porque, o también en cuanto.

\section{Pictograma 798}

Igual a pictograma 160. Significa: hombre.

$P$. ¿Y al morir el Señor Jesucristo en la cruz, murió en cuanto Dios (o) en cuanto hombre? R. Resucitó en cuanto Dios (y) en cuanto hombre.

\section{Pregunta 16}

\section{Pictograma 799}

Igual a pictograma 160. Significa: hombre. 


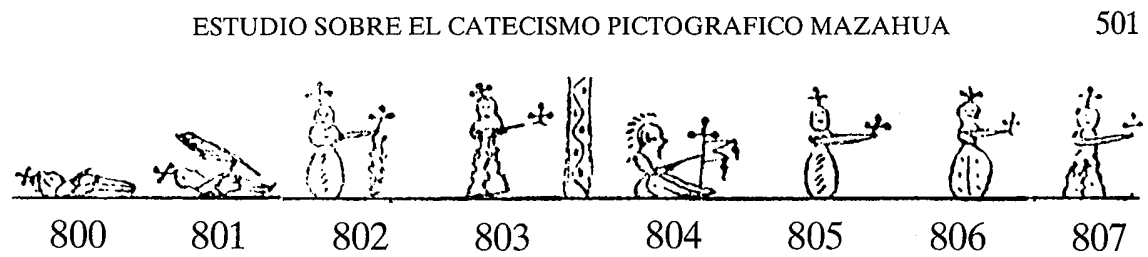

\section{Pictograma 800}

Igual a pictograma 15. Significa: murió.

\section{Pictograma 801}

Prácticamente igual a pictograma 15 , con la diferencia de que el muerto está representando con una pluma (como la del pictograma 19) entre sus manos. Significa: murió.

\section{Pictograma 802}

Igual a pictograma 464. Significa: alma.

\section{Pictograma 803}

Igual a pictograma 519. Significa: cuerpo.

\section{Pictograma 804}

Igual a pictograma 176. Significa: resucitó.

\section{Pictograma 805}

Igual a pictograma 464. Significa: alma.

\section{Pictograma 806}

Igual a pictograma 464. Significa: alma.

\section{Pictograma 807}

Igual a pictograma 519. Significa: cuerpo.

$P$. ¿Si el hombre murió, murió el alma (y) el cuerpo? R. Resucitó el alma, el alma (y) el cuerpo.

En las dos preguntas anteriores puede observarse una misma "sintaxis", ya que en ambos casos la pregunta se centra en el hecho de la muerte (del Dios y del hombre, en un caso; del cuerpo y del alma, en el otro). Sin embargo ambas respuestas se limitan a desplazar el centro de gravedad desde la muerte a la resurrección, y en ambos casos se tratan de soslayar los difíciles enunciados teológicos (complicadísimos para ser expresados en términos pictográficos muchos más simples). Con afirmar que el que resucita es Dios y hombre, y que resucita en alma y cuerpo, está salvado lo fundamental del dogma, y se ha simplificado extraordinariamente la cuestión. 


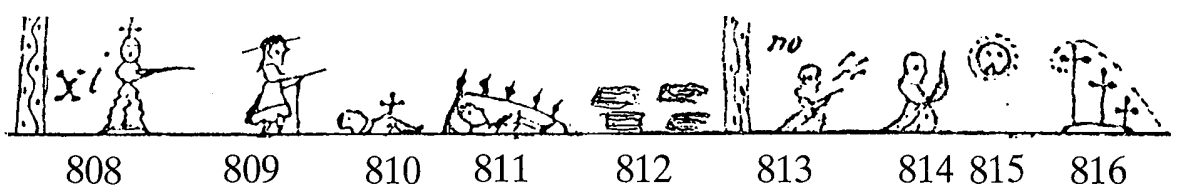

Pregunta 17

\section{Pictograma 808}

Igual a pictograma 519. Significa: cuerpo.

Pictograma 809

Igual a pictograma 160. Significa: hombre.

\section{Pictograma 810}

Igual a pictograma 15. Significa: murió.

\section{Pictograma 811}

Igual a pictograma 173. Significa: sepultado.

\section{Pictograma 812}

Igual a pictograma 204. Significa: siempre.

\section{Pictograma 813}

Igual a pictograma 687, también lleva aneja la inscripción "no". Significa precisamente: no.

\section{Pictograma 814}

Igual a pictograma 16. Significa: por, porque.

\section{Pictograma 815}

Igual a la mitad superior del pictograma 104. Significa: día.

\section{Pictograma 816}

Igual a pictograma 29 y 232. Es díficil asignar en este caso un significado exacto. No parece que corresponda el asignado al pictograma 29 ("tres cruces"). El asignado al pictograma 232 es: "después"; en este caso, la afirmación sería que Jesús recitó el día después de ser enterrado, lo que contradice la expresión tradicional "al tercer día"; si se le asignara este sentido, por el hecho de figurar tres cruces, parece que habría una falta de coherencia con el pictograma 175, que expresa la idea de "tres días" con otro tipo de representación. Sin embargo es la hipótesis que parece más plausible: al tercer día. 


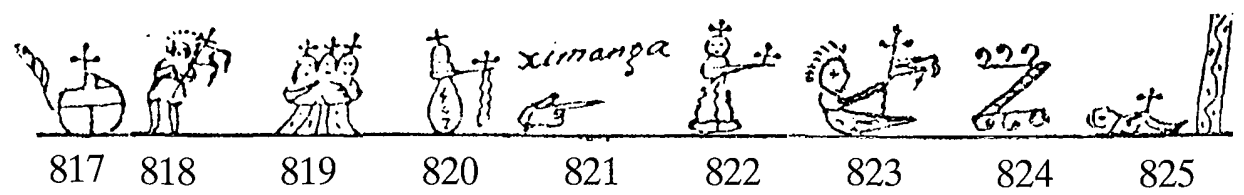

\section{Pictograma 817}

Casi igual al pictograma 97, con la particularidad de que aparece también una pluma en la parte izquierda del pictograma. Significa: en la tierra.

\section{Pictograma 818}

Una figura igual a la del pictograma 27, pero está representada de frente en lugar de hacerlo como habitualmente de perfil; la figura está algo inclinada hacia la derecha (del lector). Podría interpretarse por: como era Dios.

\section{Pictograma 819}

Igual a pictograma 197. Significa: unión, reunión.

\section{Pictograma 820}

Igual a pictograma 464. Significa: alma.

\section{Pictograma 821}

Igual a pictograma 68, más la inscripción “ximanga". Significa: y también.

\section{Pictograma 822}

Igual a pictograma 519. Significa: cuerpo.

\section{Pictograma 823}

Igual a pictograma 176. Significa: resucitó.

\section{Pictograma 824}

Dos líneas paralelas ornadas por arriba y por abajo con una especie de volutas, y unidas entre sí, por un trazo más ancho, doble, con pequeñas rayitas intermedias. El significado que podría corresponder a este pictograma con única representación en el Catecismo, sería el de: vencer.

\section{Pictograma 825}

Igual a pictograma 15. Significa: muerte.

$P$. ¿El cuerpo humano, fué muerto y sepultado para siempre? R. No, porque el día tercero (de ser) enterrado, como (era) Dios, unió el alma y también el cuerpo (y) resucitó al vencer (?) a la muerte. 


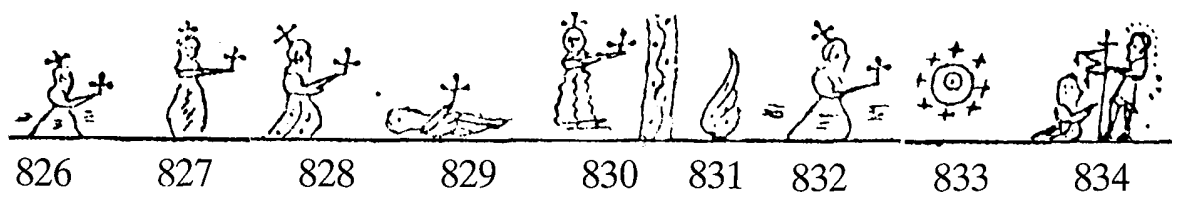

Pregunta 18

Pictograma 826

Igual a pictograma 521. Significa: consecuencias buenas.

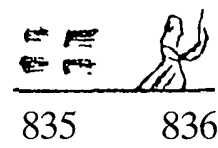

Pictograma 827

Igual a pictograma 522. Significa: alma.

Los pictogramas 826 y 827 repiten el conjunto de los pictogramas 521 y 522 , como enunciado de las obras de misericordia espirituales.

\section{Pictograma 828}

Igual a pictograma 4. Significa: muestra.

\section{Pictograma 829}

Igual a pictograma 15 . Significa: muere.

\section{Pictograma 830}

Igual a pictograma 519. Significa: cuerpo.

\section{Pictograma 831}

Igual a pictograma 50. Significa: obras.

\section{Pictograma 832}

Igual a pictograma 521. Significa: consecuencias buenas.

\section{Pictograma 833}

Igual a pictograma 99. Significa: cielo.

\section{Pictograma 834}

Similar a pictograma 27, más una persona arrodillada a la izquierda del pictograma; recuerda al pictograma 103. Su significado es: dará Dios.

\section{Pictograma 835}

Igual a pictograma 204. Significa: siempre.

\section{Pictograma 836}

Igual a pictograma 16. Significa: por, porque. 


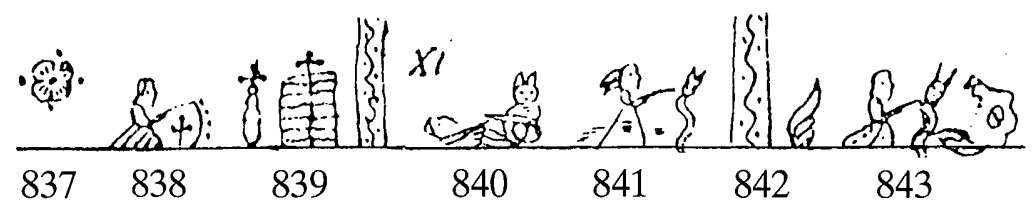

\section{Pictograma 837}

Igual a pictograma 80. Significa: provecho, premio.

\section{Pictograma 838}

Igual a pictograma 500. Significa: respetaron.

\section{Pictograma 839}

Igual a pictograma 77. Significa: mandamientos.

$P$. ¿Qué consecuencias buenas (para) el alma (se) muestran al morir el cuerpo? R. Las obras de buenas consecuencias del cielo (que) dará Dios (para) siempre por premio al respetar los mandamientos.

\section{Pregunta 19}

\section{Pictograma 840}

Un personaje caído a la izquierda del pictograma, y a la derecha, en pie, la representación del pictograma 18. El sentido conjunto de este pictograma compuesto puede ser: dominio del pecado.

\section{Pictograma 841}

Parecido al pictograma 521, pero totalmente invertido. En aquél, aparecía una persona con tres series de rayitas horizontales por delante, detrás y en el propio vestido, pero sosteniendo en la mano una cruz. Este otro pictograma es su antítesis, pues la misma persona tiene el mismo tipo de rayas, pero está señalando a la representación del pecado del pictograma 18 , cuyo cuerpo serpentiforme no está enroscado, sino en movimiento. El sentido del pictograma parece claro: consecuencias malas.

\section{Pictograma 842}

Igual a pictograma 50. Significa: obras.

\section{Pictograma 843}

Un personaje arrodillado está indicando a la representación del pecado, que parece estar saliendo de las fauces abiertas de un monstruo similar al del pictograma 22. El significado de este pictograma es: del pecado y del mal. 


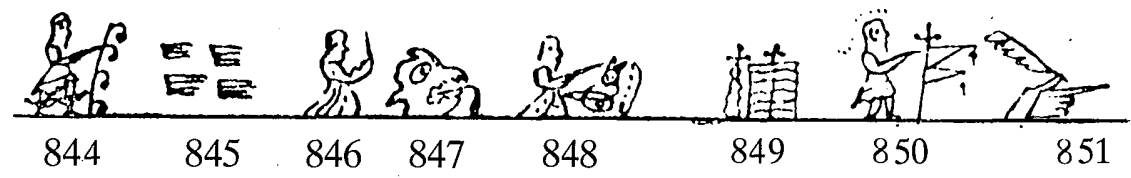

Pictograma 844

Igual a pictograma 504. Significa: prisión.

Pictograma 845

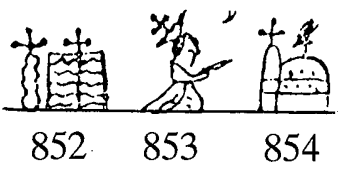

Igual a pictograma 204. Significa: siempre.

Pictograma 846

Igual a pictograma 16. Significa: por, porque.

Pictograma 847

Igual a pictograma 22. Significa: malos.

Pictograma 848

Igual a pictograma 508. Significa: no respetaron.

\section{Pictograma 849}

Igual a pictograma 77. Significa: mandamientos.

\section{Pictograma 850}

Igual a pictograma 27. Significa: Dios.

\section{Pictograma 851}

Igual a pictograma 19. Significa: y también (y tampoco).

\section{Pictograma 852}

Igual a pictograma 77. Significa: mandamientos.

\section{Pictograma 853}

Igual a pictograma 132. Significa: santa.

\section{Pictograma 854}

Igual a pictograma 69. Sìgnifica: Iglesia.

$P$. ¿El dominio del pecado, (qué) consecuencias malas (tiene)? $R$. Las obras del pecado y del mal (son) prisión (para) siempre, porque los malos no respetaron los mandamientos de Dios y tampoco los mandamientos de la santa Iglesia.

La estructura de la pregunta 19 se limita a repetir la de la pregunta 18, y ambas remiten a la frase final de las Obras de misericordia. 


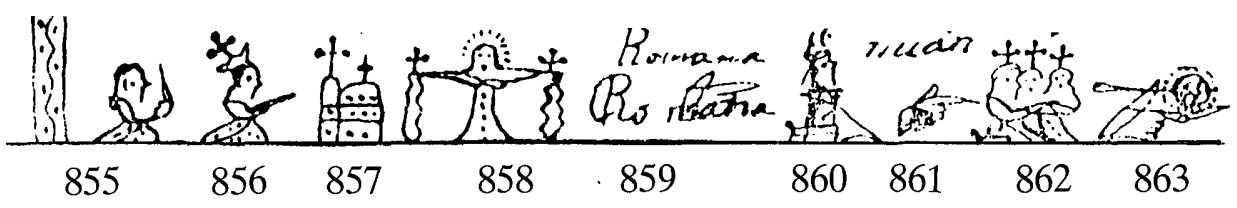

Pregunta 20

Pictograma 855

Igual a pictograma 661. Significa: quién es.

Pictograma 856

Igual a pictograma 132. Significa: santa.

Pictograma 857

Igual a pictograma 69. Significa: Iglesia.

\section{Pictograma 858}

Igual a pictograma 196. Significa: católica.

\section{Pictograma 859}

En realidad no es pictograma, sino escritura alfabética, donde aparece dos veces, con dos tipos diversos de letra, la inscripción "Romana". Posiblemente se trata de que el tlacuilo no pudo encontrar una forma aceptable de representar iconográficamente la idea, y se vió obligado a recurrir a la escritura: Romana.

\section{Pictograma 860}

Un personaje sentado tiene sobre su cabeza un tipo de sombrero extraño, como si ciñera su frente y además sobresalieran dos trazos en vertical. $\mathrm{Su}$ significado puede ser: Papa.

\section{Pictograma 861}

Igual a pictograma 68; en la parte superior aparece la leyenda "nuan". Significa: $y$.

\section{Pictograma 862}

Igual a pictograma 197. Significa: unión, reunión.

\section{Pictograma 863}

Igual a pictograma 68 , la representación de la mano tiene dibujado encima algo que recuerda, estilizado, al pictograma 2: un trazo ancho por la izquierda y estrecho hacia la derecha, más un doble círculo. Significaría: estos verdaderos. 


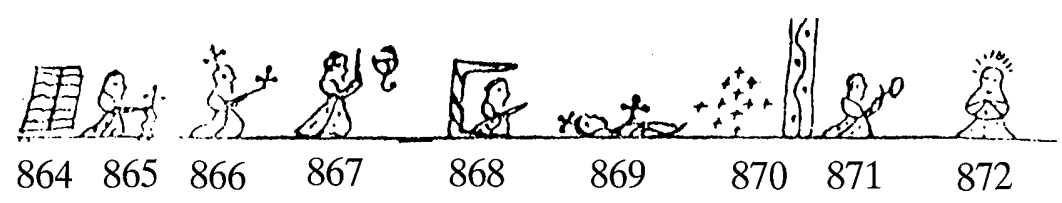

\section{Pictograma 864}

Una representación de un libro abierto, como la que figura a la derecha del pictograma 77, pero sin remate de cruz en la parte superior (ver la que aparece en el pictograma 73). Su significado podría ser: buenos.

\section{Pictograma 865}

Igual a pictograma 3. Significa: creyentes.

\section{Pictograma 866}

Igual a pictograma 4. Significa: muestran.

También, podría significar, quizá con mayor precisión: necesitan.

\section{Pictograma 867}

Igual a pictograma 378. Significa: para.

\section{Pictograma 868}

Igual a pictograma 17. Significa: librar.

\section{Pictograma 869}

Igual a pictograma 15. Significa: muerte.

\section{Pictograma 870}

Igual a pictograma 123. Significa: gracia.

P. ¿Quién es la santa Iglesia católica Romana? R. El Papa (?) y la unión de estos verdaderos (y) buenos creyentes, (que) necesitan para librar(se) de la muerte la gracia.

\section{Pregunta 21}

\section{Pictograma 871}

Igual a pictograma 661. Significa: Quién.

\section{Pictograma 872}

Igual a pictograma 87. Significa: está. 


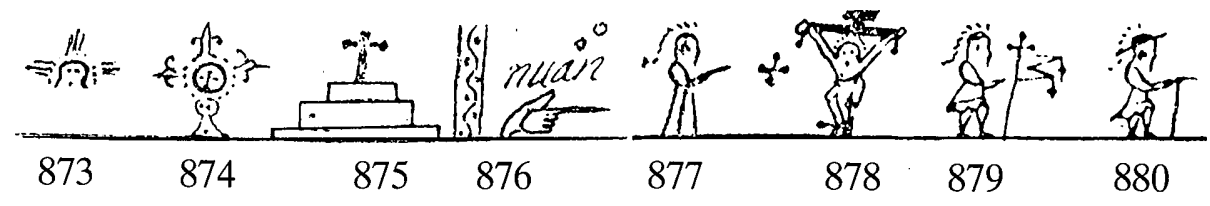

Pictograma 873

Igual a pictograma 124. Aquí parece que encaja mejor el significado de: santísimo.

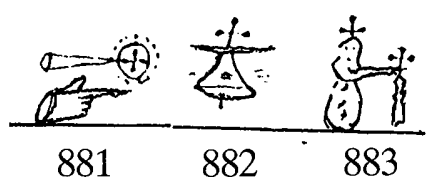

\section{Pictograma 874}

Igual a pictograma 79. Significa: sacramento.

\section{Pictograma 875}

Una cruz sobre un altar compuesto de una peana, el altar propiamente dicho y un frente elevado. Su significado es: altar.

\section{Pictograma 876}

Igual a pictograma 68; la inscripción, en este caso, es "nuân". Significa: este.

\section{Pictograma 877}

Igual a pictograma 57. Significa: Señor.

\section{Pictograma 878}

Igual a pictograma 11. Significa: Jesucristo.

\section{Pictograma 879}

Igual a pictograma 27. Significa: Dios.

\section{Pictograma 880}

Igual a pictograma 160. Significa: hombre

\section{Pictograma 881}

Igual a pictograma 2. Significa: verdadero.

\section{Pictograma 882}

Similar a pictograma 198, aparece una sola campana, de tamaño mayo que en aquel pictograma en que estaban dibujadas dos. Su significado es: santo.

\section{Pictograma 883}

Igual a pictograma 464. Significa: alma. 


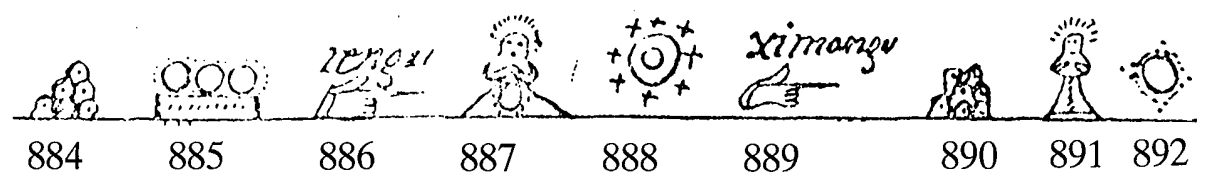

\section{Pictograma 884}

Igual a pictograma 1. Significa: toda.

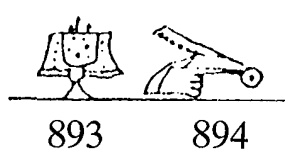

\section{Pictograma 885}

Tres círculos con aureola de puntos alrededor de ellos están sobre una mesa. Su posible significado sería: entero.

\section{Pictograma 886}

Igual a pictograma 68; en la parte superior del pictograma aparece escrito "rengu". Significa: $y$ también.

\section{Pictograma 887}

Igual a pictograma 87. Significa: está.

\section{Pictograma 888}

Igual a pictograma 88. Significa: cielo.

\section{Pictograma 889}

Igual a pictograma 68 , con la adición de la inscripción "ximangu". Significa: y también.

\section{Pictograma 890}

Igual a pictograma 2. Significa: todo.

\section{Pictograma 891}

Igual a pictograma 87. Significa: está.

\section{Pictograma 892}

Igual a pictograma 732. En este caso parece que encaja más válidamente el significado de: pan, haciendo referencia al pan consagrado.

\section{Pictograma 893}

Una copa o cáliz cubierto con el cubrecáliz. Su significado sería: vino, aludiendo, como en el pictograma anterior, al vino consagrado.

\section{Pictograma 894}

Igual a pictograma 19. Significa: así como. 


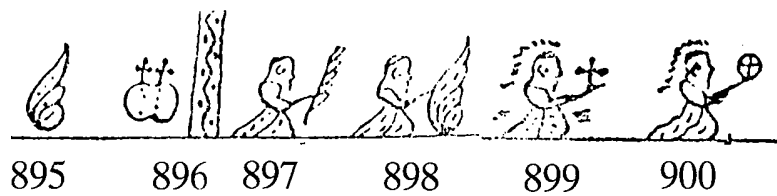

\section{Pictograma 895}

Igual a pictograma 50. Significa: hacer.

Sospecho que en este caso ha habido un error, porque debería haber aparecido el pictograma 1, que significa "todo", pues la afirmación sería que "está en todas partes". La explicación del error puede encontrarse en el hecho de que en numerosas ocasiones aparecen juntos el pictograma 1 y el 50: "todo-hacedor", e incluso fundidos, como en el pictograma 149. El tlacuilo cometería un despiste y dibujaría uno cuando en realidad querría haber dibujado el otro.

\section{Pictograma 896}

Dos círculos secantes aparecen con una brevísima línea de puntitos en cada uno de ellos de arriba a abajo. Ambos están rematados por sendas cruces. Su significado podría ser: partes.

$P$. ¿Quién está en el santísimo sacramento del altar? R. Este Señor Jesucristo, Dios (y) hombre verdadero, (con su) santa alma toda entera; también está (en) el cielo; y también todo está (en) el pan y el vino, así como (en) todas (?) partes (?).

\section{Pregunta 22}

\section{Pictograma 897}

Un personaje arrodillado sostiene un bastón en el que aparecen una serie de adornos, como si se tratara de plumas (?) insertas en él. Su significado puede ser: (Qué) Debe.

\section{Pictograma 898}

Igual a pictograma 50. Significa: hacer

\section{Pictograma 899}

Parecido a los pictogramas 4 y 336, una persona con rasgos divinos (aureola) tiene en sus manos una cruz. Su sentido podría ser: recibir.

\section{Pictograma 900}

Igual a pictograma 338. Significa: comunión. 


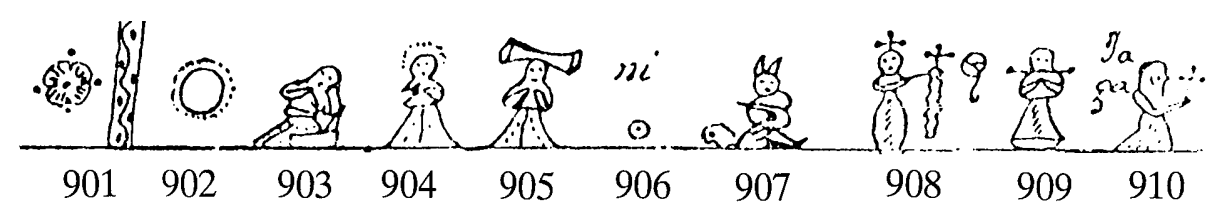

Pictograma 901

Igual a pictograma 80 . Significa: provecho.

\section{Pictograma 902}

Similar a la primera parte del pictograma 102, significaría: el día.

\section{Pictograma 903}

Una persona se inclina hacia la parte derecha del pictograma, mientras permanece arrodillado. Podría interpretarse como: anterior.

\section{Pictograma 904}

Igual a pictograma 87. Significa: estar.

\section{Pictograma 905}

Igual a pictograma 342; la diferencia es que en esta ocasión el dibujo es más grande y nítido: un personaje similar al del pictograma anterior sostiene sobre su cabeza un gran travesaño o palo. Significa: ayunar.

\section{Pictograma 906}

Igual a pictograma 638. Sin embargo, aparece en la parte superior la leyenda "ni", que podría dar la pista de un nuevo significado: $y$ no.

\section{Pictograma 907}

Igual a pictograma 840 . Significa: dominio del pecado.

\section{Pictograma 908}

Similar a pictograma 464, la representación del alma tiene una de las habituales "cuerdas cerradas", como la del pictograma 3. Su significado sería: alma.

\section{Pictograma 909}

Figura similar a la del pictograma 87, tiene a ambos lados, a la altura del cuello, una línea rematada en una pequeña bola obscura.

No he encontrado un sentido apropiado para este pictograma.

\section{Pictograma 910}

Similar a pictograma 4, aunque no tenga cruz sobre la cabeza; en cambio, en la parte superior del pictograma aparece la inscripción "Ja ga". Significa: mostrar. 


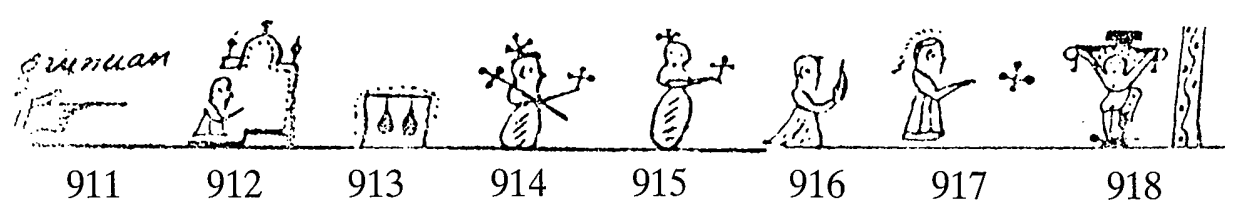

Pictograma 911

Igual a pictograma 68. Le acompaña la anotación "gunuan". Significa: $y$.

\section{Pictograma 912}

Sobre el trasfondo de una iglesia (que recuerda al pictograma 69), aparecen dos banzos de una escalera que está subiendo una persona que aparece en la parte inferior del pictograma. Su significado es: entrar en la iglesia.

\section{Pictograma 913}

Un rectángulo hecho con línea continua y orlado por el exterior por línea punteada, alberga en su interior dos pequeños colgantes más anchos por la parte inferior, que no es sencillo precisar de qué se trata.

No he encontrado un sentido lógico para el presente pictograma.

\section{Pictograma 914}

Una representación igual a la del alma (pictograma 464) vista de perfil, tiene sobre su hombre un bastón rematado en la habitual cruz. Podría ser su significado: penitencia.

\section{Pictograma 915}

Igual a pictograma 464. Significa: alma.

\section{Pictograma 916}

Igual a pictograma 16. Significa: por, porque.

\section{Pictograma 917}

Igual a pictograma 57. Significa: Señor.

\section{Pictograma 918}

Igual a pictograma 11. Significa: Jesucristo.

$P$. ¿(Qué) debe hacer (para) recibir la comunión (con) provecho? $R$. El día anterior(?) estar (en) ayunas; y no (bajo) el dominio del pecado el alma (...) mostrar; y entrar en la iglesia (...) penitencia del alma, porque (es) el Señor Jesucristo. 


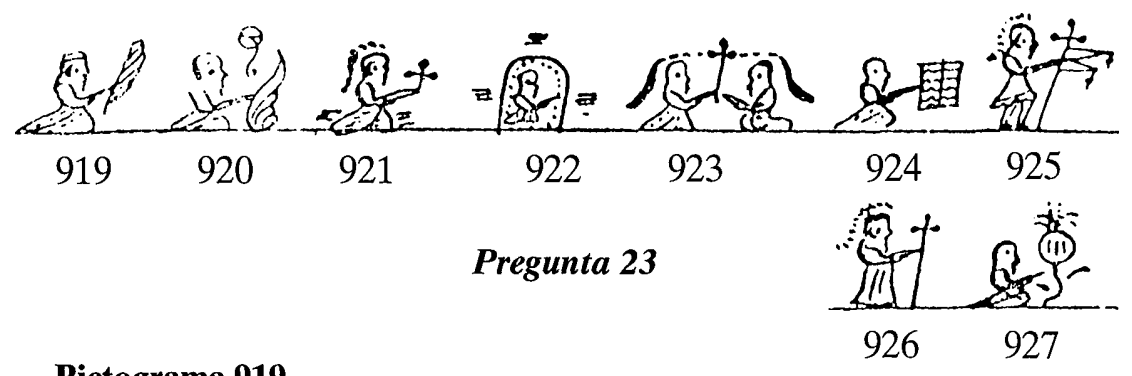

Pictograma 919

Igual a pictograma 897. Significa: (Qué) debe.

\section{Pictograma 920}

Igual a pictograma 50. Significa: hacer.

\section{Pictograma 921}

Igual a pictograma 988. Significa: recibir.

\section{Pictograma 922}

Una persona está en un recinto formado por una doble línea, una continua y otra punteada, que le rodea enteramente; por arriba y a los lados aparecen tres grupos de tres rayitas horizontales. Podría significar: salvación.

\section{Pictograma 923}

Dos personas arrodilladas frente a frente sostienen en sus manos una cruz; las dos personas están amparadas o cubiertas por un rasgo punteado que se extiende en horizontal sobre sus cabezas, y luego desciende haciendo una curva hacia ambos lados. El único sentido que me parece viable sería: los que veneran la cruz.

\section{Pictograma 924}

Igual a pictograma 494. Significa: los buenos .

Pictograma 925

Igual a pictograma 27. Significa: Dios.

Pictograma 926

Igual a pictograma 188. Significa: juzgar.

Pictograma 927

Igual a pictograma 496. Significa: premiar. 


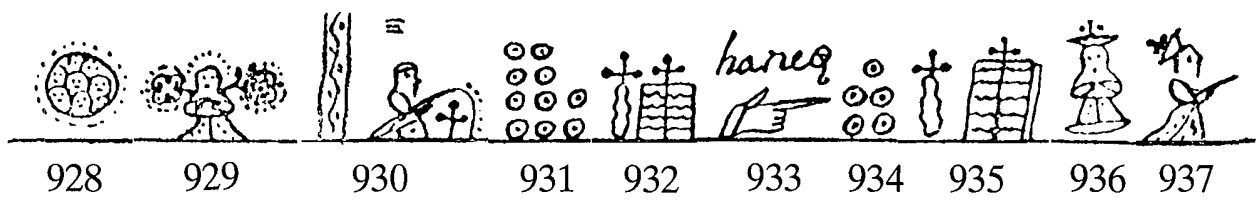

\section{Pictograma 928}

Un gran círculo, similar al que representa la idea de "día" (pictograma 902) tiene en su interior dibujada muchas caras. Podría tratarse de una combinación del pictograma 902 y del pictograma 2, en cuyo caso significaría: todos los días. También encaja, incluso mejor, desde el punto de vista del sentido lógico, el significado de: el último día.

No obstante, es necesario anotar que existe también un parecido con el pictograma 249 .

\section{Pictograma 929}

Igual a pictograma 120. Significa: glorifique.

\section{Pictograma 930}

Igual a pictograma 500. Significa: respetar

\section{Pictograma 931}

Igual a pictograma 255. Significa: diez.

\section{Pictograma 932}

Igual a pictograma 77. Significa: mandamientos.

\section{Pictograma 933}

Igual a pictograma 68; la inscripción que aparece en la parte superior es "haneq". Significa: y también.

\section{Pictograma 934}

Igual a pictograma 282. Significa: cinco.

\section{Pictograma 935}

Igual a pictograma 77. Significa: mandamientos.

\section{Pictograma 936}

Igual a pictograma 209. En este caso podría significar: madre.

\section{Pictograma 937}

Igual a pictograma 132. Significa: santa. 


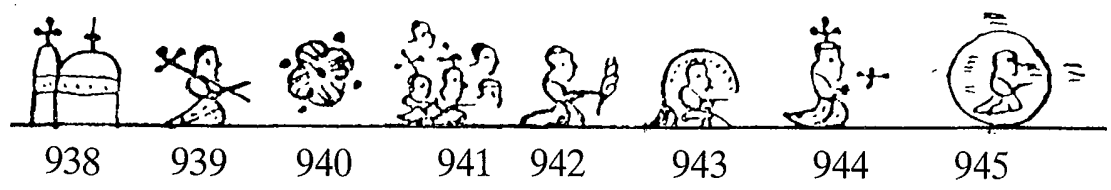

\section{Pictograma 938}

Igual a pictograma 69. Significa: Iglesia.

\section{Pictograma 939}

Igual a pictograma 914. Significa: penitencia.

\section{Pictograma 940}

Igual a pictograma 80. Significa: provecho.

\section{Pictograma 941}

Cinco cabezas de personas aparecen dibujadas formando un grupo. Podría significar: muchos.

Se invierte en este pictograma el sentido de la lectura, al llegar a la última banda de las destinadas a las preguntas y respuestas. Sin embargo, no está señalado con una flechita como sucedía en ocasiones anteriores, ya que tales flechitas han desaparecido a partir del pictograma 635, precisamente al iniciarse las preguntas.

\section{Pictograma 942}

Igual a pictograma 897. Significa: debe.

\section{Pictograma 943}

Igual a pictograma 25. Significa: continuar.

\section{Pictograma 944}

Igual a pictograma 4. Significa: muestra.

\section{Pictograma 945}

Un círculo en cuyo interior aparece una persona arrodillada, junto a una serie de rayas horizontales a uno y otro lado; en el exterior del círculo aparecen dos grupos de tres rayas horizontales arriba y a la izquierda del pictograma. Su significado podría ser: promesas.

Comparándolo con el pictograma 249, que representa la idea de "promesas", hay un cierto parecido remoto, aunque no exista en cuanto a la representación. 


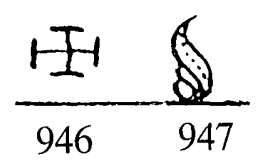

\section{Pictograma 946}

Igual a pictograma 50. Significa: (se) haga.

\section{Pictograma 947}

Igual a pictograma 118. Significa: Jesús.

P. ¿(Qué) deben hacer (para) recibir la salvación los que veneran la cruz, los buenos, (que) Dios juzgará el último día y glorificará? $R$. Respetar los diez mandamientos así como los cinco mandamientos de la madre santa Iglesia, (hacer) penitencia con provecho, (pues) muchos (?) deben continuar (para) mostrar las promesas(?). (Así) se haga, Jesús. 


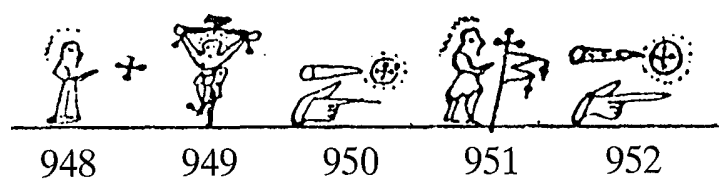

\section{DECIMOCUARTA PARTE}

\section{SEÑOR MIO JESUCRISTO}

Como ya he advertido en la introducción, esta parte pasó desapercibida a otros autores que han escrito sobre este Catecismo, y no la han incluído en sus descripciones. Puede deberse al hecho de que no está precedida, como sucede en otros casos, de un rótulo escrito en el propio texto que así lo advierta.

Sin embargo, es claro que se trata de otra parte perfectamente diferenciada. En primer lugar, porque la parte decimo tercera, que le precede inmediatamente, termina con el "Amén Jesús" de rigor, lo cual está marcando que si ése (pictogramas 946 y 947) es el final de una parte, lo que le sigue está perfectamente diferenciado como algo diverso. En segundo lugar, por si la advertencia anterior no fuera suficiente como para caer en la cuenta, el hecho mismo del contenido de esta parte se presenta no como continuidad de algo que le precede inmediatamente, sino como otro formulario distinto; al analizarlo, he podido comprobar que se trata del "Señor mío Jesucristo", conocido también con la expresión "Acto de contrición".

\section{Pictograma 948}

Igual a pictograma 57. Significa: Señor.

\section{Pictograma 949}

Igual a pictograma 11. Significa: Jesucristo.

\section{Pictograma 950}

Igual a pictograma 2. Significa: verdadero.

\section{Pictograma 951}

Igual a pictograma 27. Significa: Dios.

\section{Pictograma 952}

Igual a pictograma 2. Significa: verdadero. 


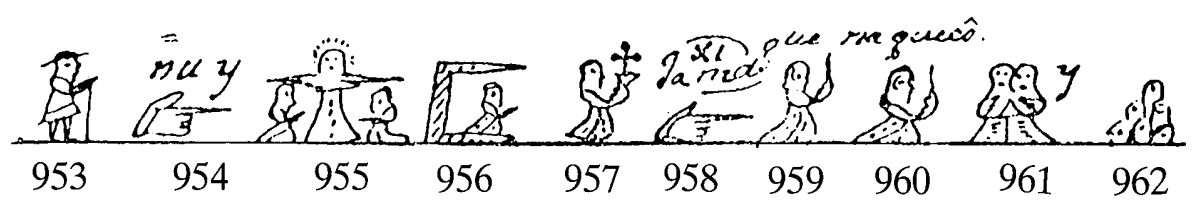

\section{Pictograma 953}

Igual a pictograma 160. Significa: hombre.

\section{Pictograma 954}

Igual a pictograma 68, con la anotación "nuy" en la parte superior del pictograma. Significa: $y$.

\section{Pictograma 955}

Igual a pictograma 150. Significa: creador.

\section{Pictograma 956}

Igual a pictograma 17. Significa: librar.

\section{Pictograma 957}

Igual a pictograma 910. Significaría: mostrar, pero no parece que éste sea el significado que mejor encaje en el desarrollo de la oración.

\section{Pictograma 958}

Igual a pictograma 68. La parte superior del pictograma está ocupada por una leyenda que no es fácil leer, por el orden exacto en que haya que situar las sílabas, pues en la parte más alta aparece la sílaba "xi”, y en una línea inferior, pero iniciando una mayúscula aparece escrito "Jama". Desconozco si hay que leer "Jamaxi",o "Jaxima". El pictograma como tal significa: $y$.

\section{Pictograma 959}

Igual a pictograma 16. Significa: por.

\section{Pictograma 960}

Igual a pictograma 661. Significa: quien es.

Sobre estos dos pictogramas aparece escrito con caracteres alfabéticos: "guae maguecô".

\section{Pictograma 961}

Igual a pictograma 264. Significa: amar.

\section{Pictograma 962}

Igual a pictograma 1. Significa: todo. 


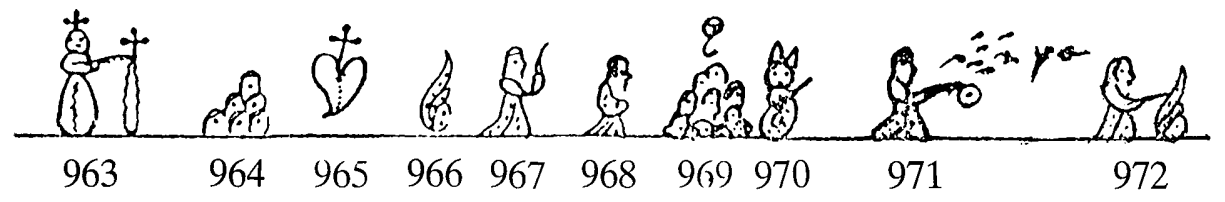

Pictograma 963

Igual a pictograma 464. Significa: alma.

\section{Pictograma 964}

Igual a pictograma 1. Significa: todo.

\section{Pictograma 965}

Igual a pictograma 8. Significa: corazón.

\section{Pictograma 966}

Igual a pictograma 50. Significa: hacer.

\section{Pictograma 967}

Igual a pictograma 16. Significa: por.

\section{Pictograma 968}

Un personaje arrodillado está en una postura inexpresiva, ocultando la mano recogida sobre el pecho, de manera que ni siquiera aparece dibujada. Podría significar, por el desarrollo de la oración: acordarme.

\section{Pictograma 969}

Igual a pictograma 1. Significa: todos.

\section{Pictograma 970}

Igual a pictograma 18. Significa: pecados.

\section{Pictograma 971}

Igual a pictograma 43. Significa: decir.

\section{Pictograma 972}

Pictograma compuesto de un personaje arrodillado, más el dibujo correspondiente al pictograma 50. Significa: hacer.

Sobre el pictograma aparece escrito: "ya".

Sin embargo, el sentido de la oración en este punto emplea el sentido negativo: “... propongo no hacer...". 


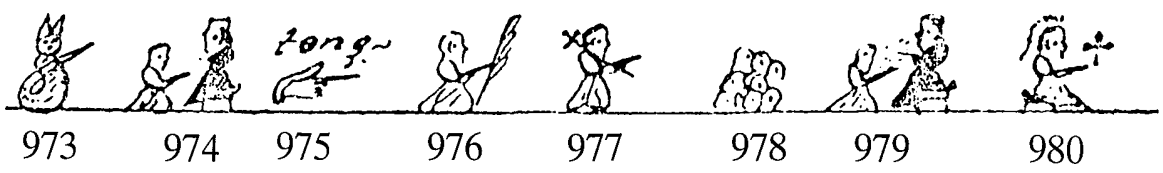

Pictograma 973

Igual a pictograma 18. Significa: pecado.

Pictograma 974

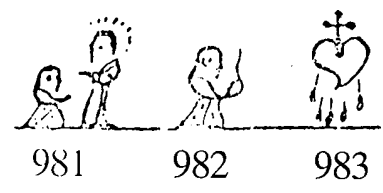

Igual a pictograma 327. Significa: confesar(me).

\section{Pictograma 975}

Igual a pictograma 68. Sobre la representación aparece el rótulo "tong". Significa: $y$.

\section{Pictograma 976}

Igual a pictograma 897. En este caso, el contexto aconseja modificar el sentido señalado entonces de "deber" por el significado de: cumplir.

\section{Pictograma 977}

Igual a pictograma 914. Significa: penitencia.

\section{Pictograma 978}

Igual a pictograma 1. Significa: todo.

\section{Pictograma 979}

Parecido al pictograma 974, la indicación que el dibujo señala con toda precisión es la de que el sacerdote está hablando al penitente. Por tanto, su significado, reforzado por el sentido de la oración sería: impuesta, mandada.

\section{Pictograma 980}

Igual a pictograma 899. Significa: recibir.

\section{Pictograma 981}

Igual a pictograma 105. Significa: perdón.

\section{Pictograma 982}

Igual a pictograma 16. Significa: por.

\section{Pictograma 983}

Parecido a pictograma 8, aparece un corazón del que caen cinco grandes gotas. Su significado es: sufrimiento del corazón. 


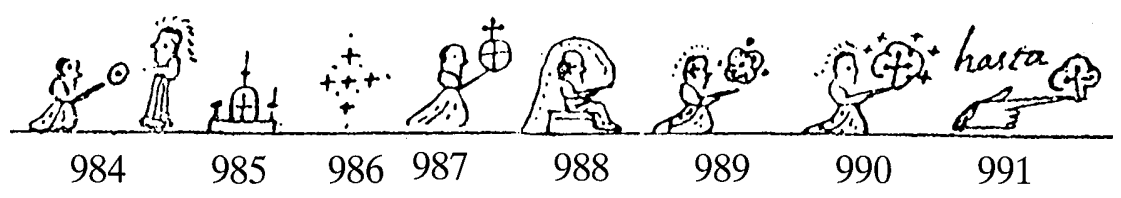

\section{Pictograma 984}

Igual a pictograma 103. Significa: $d a(m e)$.

\section{Pictograma 985}

Igual a pictograma 383. Significa: venerada.

\section{Pictograma 986}

Igual a pictograma 123. Significa: gracia.

\section{Pictograma 987}

Parecido a pictograma 16, el personaje tiene en su mano un círculo partido en cuatro, rematado por una cruz (No se corresponde con el pictograma 97, pues la representación de la "tierra" aparece divida en tres partes: la semiesfera inferior, y la dos partes de la semiesfera superior). Su significado podría ser el de: para poder.

\section{Pictograma 988}

Igual a pictograma 25. Significa: continuar.

\section{Pictograma 989}

Semejante al pictograma 80 , con la diferencia de que el tema central del pictograma está sostenido por un personaje arrodillado. Su sentido es: provechoso.

\section{Pictograma 990}

Casi igual a pictograma 89 , pero además de la cruz nimbada que el personaje sostiene en sus manos, en el presente pictograma aparece, además, adornada con crucecitas, como ocurría en el pictograma 130 para añadir la idea de "bendita". Significaría, pues: bendita reverencia.

\section{Pictograma 991}

Casi igual a pictograma 68, pero la mano tiene una cruz nimbada, semejante a la que aparece en el pictograma anterior. Sin embargo, aparece en la parte superior muy clara la inscripción "hasta", que parece que es lo que mejor cuadra al desarrollo de la oración. Significa, en consecuencia: hasta. 


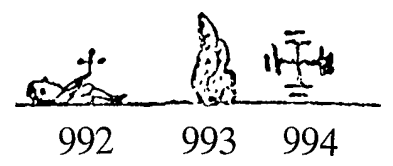

\section{Pictograma 992}

Igual a pictograma 15. Significa: muerte.

\section{Pictograma 993}

Igual a pictograma 50. Significa: (se) haga.

\section{Pictograma 994}

Igual a pictograma 118. Significa: Jesús.

Es el momento de recapitular todo lo que corresponde a esta oración: Señor Jesucristo, verdadero Dios, verdadero hombre y creador, liberador (...) y por quien (eres), (te) amo de toda alma (y) de todo corazón. Haré por acordarme (?) de todos los pecados. Digo (que) (no) (?) haré pecados; confesarme y cumplir la penitencia del todo impuesta; recibiré el perdón por el sufrimiento del corazón. Dame la venerada gracia para poder (?) continuar la provechosa bendita reverencia hasta la muerte. (Así) se haga, Jesús.

Al llegar al final del desciframiento es el momento de recoger los fragmentos dispersos de cada uno de los formularios y oraciones para verlos todos juntos. En el mismo orden en que van apareciendo en el texto pictográfico, he aquí su sentido completo, hasta donde me ha sido posible llevar a cabo la tarea de desciframiento e interpretación.

\section{TODO FIEL CRISTIANO}

Todo verdadero creyente muestra tener(?) devoción (de) todo corazón a la santa cruz de Jesucristo. En la cruz entonces (?) quiso (?) morir por redimir(nos) del pecado y también del enemigo malo. Todos los buenos mantienen la señal (?) de Dios con estas tres cruces: la primera en la frente porque (nos) libre Dios de los malos pensamientos; la segunda en la boca, porque (nos) libre Dios de las malas palabras; la tercera en el pecho, porque (nos) libre Dios de las malas acciones. Y diga: Por la señal de la cruz de los enemigos libra(nos) Señor Dios nuestro (?) en el nombre del Padre, del Hijo, del Espíritu Santo. (Así) se haga. 


\section{DIVISION DE LA DOCTRINA CRISTIANA}

Ahora creo (en) el pecado, y (en) la Iglesia (que) tiene (?), dice y enseña (?) a creer y a hacer: la fe, los mandamientos, las oraciones (?), los sacramentos (con) provecho (nos) muestra; aprovecha lo que dice ....

\section{PADRENUESTRO}

Padre (que) estás en el cielo, reverenciado tu nombre. Venga (?) (tu) reino. (Se) haga (tu) voluntad tanto en la tierra como en el cielo. Este pan (que) necesitamos cada día danos(lo) cada día. Perdóna(nos) los pecados nuestros así como nosotros (?) perdonamos los pecados nuestros. No nos dejes (?) caer (en) hacer pecado, sino líbra(nos) del mal. (Así) se haga Jesús.

\section{AVEMARIA}

Dios (te) glorifique, María, llena de gracia. La divinidad está con(tigo). Bendita (entre) todas las mujeres, bendito el fruto del vientre, Jesús. Santa María, Santa madre de Dios, ruega por nosotros pecadores ahora y también a la muerte. Así se haga, Jesús.

\section{CREDO}

(En la cruz). Creo (en) Dios Padre todohacedor, creador del cielo y la tierra. Creo (en) Jesucristo, (su) único Hijo, Señor, hecho hombre (por) obra del Espíritu Santo (y) la santa virgen (?) María. Sufrió (?) pasión a las órdenes de Poncio Pilato. Crucificado, muerto (y) sepultado, bajó al infierno; al tercer día resucitó de entre los muertos. Subió al cielo; sentado allí a la bendita mano derecha de Dios Padre todohacedor. (Desde) allí vendrá (para) a los hombres juzgar, a vivos así como a muertos. Creo (en) el Espíritu Santo; la santa Iglesia católica; la comunión de los santos; el perdón de los pecados; la resurrección de la carne (?); la vida eterna. (Así) se haga, Jesús.

\section{SALVE}

Dios (te) glorifique, María, misericordiosa eres. Muy dulce esperanza, Dios (te) glorifique. A tí (nos) dirigimos, desterrados hijos de Eva (?). A tí suplicamos (con) gemidos y lloros (en) este valle (?) de lágrimas. María, pro- 
tectora nuestra (?), vuelve (tus) ojos de misericordia y después (?) del destierro muestra(nos) a Jesús, bendito fruto del vientre. ¡Oh misericordiosa!, ;Oh hacedora de misericordia!, ;Oh muy dulce, dulce virgen! Santa María ruega; santa madre de Dios dignos muestra(nos) de las promesas de Jesucristo. (Así) se haga, Jesús.

\section{MANDAMIENTOS DE DIOS}

Los mandamientos de Dios (son) diez; los tres primeros (son) (para) el nombre de Dios; estos siete (son) (para) provecho del prójimo. El primero, amar a Dios más que a lo creado. El segundo, el nombre de Dios (se) manda respetar. El tercero, santificar (?) las fiestas. El cuarto, honrar padre (y) madre. El quinto (no) matar. El sexto, (no) fornicar. El séptimo, (no) robar. El octavo, (no) enredar las palabras. El noveno, (no) desear la mujer del prójimo. El décimo (no) desear los bienes (suyos). Estos diez mandamientos (se) encierran en dos: amar a Dios más que a lo creado; y al prójimo así como a tí. (Así) se haga, Jesús.

\section{MANDAMIENTOS DE LA IGLESIA}

Los mandamientos de la santa Iglesia (son) cinco. El primero, acudir a misa los creyentes (en) las fiestas, así como respetar las fiestas. El segundo, (en) la confesión decir (los pecados) una vez (?) (cada) año (...) (según) Dios, (o) (cada) medio año; (se) manda (si) espera peligro de muerte (?), o (si) (ha de) comulgar. El tercero, comulgar se manda (por) Pascua florida. El cuarto, ayunar (?) (lo) manda la santa madre Iglesia. El quinto, pagar (?) de los bienes a la Iglesia de Dios. (Así) se haga, Jesús.

\section{SACRAMENTOS}

Los sacramentos de la santa madre Iglesia (son) siete. El primero, bautismo; el segundo, confirmación; el tercero, confesión; el cuarto, comunión; el quinto, extremaunción; el sexto, orden de padre; (y) el séptimo, matrimonio. (Así) se haga, Jesús.

\section{ARTICULOS DE LA FE}

Los artículos de la fe (son) catorce. Siete para el nombre de Dios; siete (para) la venerada humanidad (?) del Señor Jescristo, Dios (y) hombre verdadero. Entonces, así (los) del venerado Dios (son) todos estos: El primero, creer (en) un único Dios todo(hacedor). El segundo, creer que es la divinidad 
del Padre. El tercero, creer que es la divinidad del Hijo. El cuarto, creer que es la divinidad del Espíritu Santo. El quinto, creer que es creador.El sexto, creer que salva. El séptimo, creer que glorifica.

Entonces, así (los) del venerado Dios (son) todos estos: El primero, creer que el Señor Jesucristo (se) hizo hombre, encarnó (?) por obra del Espíritu Santo. El segundo, creer que nació (de) santa María (que) es siempre virgen, (según) (lo) mandado María en el parto (y) después del parto. El tercero, creer que el Señor murió, padeció por liberar(nos) (del) pecado. El cuarto, creer que descendió a los infiernos; el Señor sacó las ánimas de los santos padres (que) esperaban (y) creían su santa (y) bendita llegada. El quinto, creer que resucitó al tercer día de entre los muertos. El sexto, creer que subió al cielo, sentado a la bendita mano derecha de la divinidad del Padre todohacedor. El séptimo creer que desde allí vendrá a juzgar a vivos y también muertos, a saber, (a) los buenos aprovechará el premio de la gloria, porque aprovecharon (a) respetar los mandamientos; y también (a) los malos a la prisión del castigo eterno, porque los malos pecaron (contra) los mandamientos del Señor Jesucristo. (Así) se haga, Jesús.

\section{OBRAS DE MISERICORDIA}

Las obras de misericordia (son) catorce: siete (que) muestra (o necesita) el cuerpo; (y) siete consecuencias buenas (para) el alma.

Las siete (que) liberan el cuerpo (?) son éstas (?): la primera, visitar a los enfermos; la segunda, dar comida al hambriento; la tercera, dar bebida al sediento; la cuarta, vestir al desnudo; la quinta, acoger al viajero; la sexta (?) liberar al (que) cayó en prisión; la séptima, enterrar a los muertos.

Las siete (que) liberan el alma (?) son éstas(?): la primera, enseñar al ignorante; la segunda, premiar (con) provechosas palabras de consecuencias buenas; la tercera, corregir al errado; la cuarta, perdonar las injurias (que salen) del mal corazón; la quinta, consolar al triste; la sexta, respetar por Dios la vida del prójimo; la séptima, rogar a Dios (por) los vivos y también (por) los muertos. (Así) se haga, Jesús.

\section{YO PECADOR}

Yo, pecador, confieso a Dios todohacedor, a la santa siempre virgen María, y a San Miguel arcángel y san Juan Bautista, los santos apóstoles Pedro (y) Pablo, todos los santos y a tí, padre: yo pequé (con) malos pensa- 
mientos, palabras y obras yo pequé, yo pequé, yo pequé mucho. Por eso (?) ruego que (?) santa siempre virgen María, que san Miguel arcángel, que san Juan Bautista, los santos apóstoles Pedro (y) Pablos, todos los santos, y tú, padre, rueguen a Dios (y) a Jesucristo. (Así) se haga, Jesús.

\section{PREGUNTAS Y RESPUESTAS}

P. ¿Cuántos dioses hay? R. Un único Dios verdadero.

$P$. ¿(Dónde) está Dios? R. (En) el cielo (y) la tierra este único está.

$P$. ¿El creador del cielo (y) tierra es también todohacedor? $R$. (Sí), porque (es) Dios Señor.

P. ¿Quién es Dios Señor? R. Es la santisima Trinidad.

$P$. ¿Quién es la santísima Trinidad? R. Es Padre, Hijo (y) Espiritu Santo, tres personas iguales, (pero) un único Dios verdadero.

P. ¿El Padre (es) Dios? R. Sí, (es) divinidad.

P. ¿El Hijo (es) Dios? R. Sí, (es) divinidad.

$P$. ¿El Espíritu Santo (es) Dios? R. Sí, (es) divinidad.

$P$. ¿(Son) tres dioses? R. No, un único Dios verdadero, porque en Dios hay tres en unión (de) todas las personas divinas; porque es respeto (o misterio) lo que está en el corazón de la divinidad.

$P$. ¿(Qué) persona divina de la santísima Trinidad se hizo hombre? $R$. Esta segunda persona divina que es el Hijo (...) quien hecho hombre (es) el Señor Jesucristo.

$P$. ¿Quién es Jesucristo? R. Verdadero Dios (y) verdadero hombre.

$P$. ¿Cómo se hizo hombre Jesucristo? R. Al mandar [el Espíritu Santo] (que) se hiciese (su) cuerpo, está (en) el vientre de María, santa María, (por) obra del Espiritu Santo, permanece virgen y también (es) verdadera madre de Dios.

P. ¿Por qué se hizo hombre el único Hijo de Dios? R. Por liberarnos del pecado.

$P$. ¿Cómo hizo el Señor Jesucristo en esta tierra (para) liberarnos? $R$. Padeció a las órdenes de Poncio Pilato; (fue) crucificado, muerto (y) sepultado; bajó al infierno; al tercer día resucitó de entre los muertos; subió al cielo; (está) sentado a la bendita mano derecha de Dios Padre todohacedor; desde allí vendrá (a) juzgar (a) vivos y muertos.

$P$. ¿Y al morir el Señor Jesucristo en la cruz, murió en cuanto Dios (o) en cuanto hombre? R. Resucitó en cuanto Dios (y) en cuanto hombre.

$P$. ¿Si el hombre murió, murió el alma (y) el cuerpo? R. Resucitó el alma, el alma (y) el cuerpo. 
$P$. ¿El cuerpo humano, fué muerto y sepultado para siempre? $R$. No, porque el día tercero (de ser) enterrado, como (era) Dios, unió el alma y también el cuerpo (y) resucitó al vencer (?) a la muerte.

$P$. ¿Qué consecuencias buenas (para) el alma (se) muestran al morir el cuerpo? R. Las obras de buenas consecuencias del cielo (que) dará Dios (para siempre por premio al respetar los mandamientos.

$P$. ¿El dominio del pecado, (qué) consecuencias malas (tiene)? R. Las obras del pecado y del mal (son) prisión (para) siempre, porque los malos no respetaron los mandamientos de Dios y tampoco los mandamientos de la santa Iglesia.

P. ¿Quién es la santa Iglesia católica Romana? R. El Papa (?) y la unión de estos verdaderos (y) buenos creyentes, (que) necesitan para librar(se) de la muerte la gracia.

$P$. ¿Quién está en el santísimo sacramento del altar? R. Este Señor Jesucristo, Dios (y) hombre verdadero, (con su) santa alma toda entera; también está (en) el cielo; y también todo está (en) el pan y el vino, así como (en) todas (?) partes (?).

$P$. ¿(Qué) debe hacer (para) recibir la comunión (con) provecho? $R$. El día anterior(?) estar (en) ayunas; y no (bajo) el dominio del pecado el alma (...) mostrar; y entrar en la iglesia (...) penitencia del alma, porque (es) el Señor Jesucristo.

$P$. ¿(Qué) deben hacer (para) recibir la salvación los que veneran la cruz, los buenos, (que) Dios juzgará el último día y glorificará? R. Respetar los diez mandamientos así como los cinco mandamientos de la madre santa Iglesia, (hacer) penitencia con provecho, (pues) muchos (?) deben continuar (para) mostrar las promesas(?). (Así) se haga, Jesús.

\section{SEÑOR MIO JESUCRISTO}

Señor Jesucristo, verdadero Dios, verdadero hombre y creador, liberador (...) y por quien (eres), (te) amo de toda alma (y) de todo corazón. Haré por acordarme (?) de todos los pecados. Digo (que) (no) (?) haré pecados; confesarme y cumplir la penitencia del todo impuesta; recibiré el perdón por el sufrimiento del corazón. Dame la venerada gracia para poder (?) continuar la provechosa bendita reverencia hasta la muerte. (Así) se haga, Jesús.

LUIS RESINES

Estudio Teológico Agustiniano Valladolid 